MAPK Pathway Regulates Bud Emergence_ Prabhakar et al.

\title{
1 Regulation of Bud Emergence by a MAPK Pathway
}

2 by Aditi Prabhakar, Jacky Chow, Alan J. Siegel, and Paul J. Cullen ${ }^{\dagger}$

3 Department of Biological Sciences, University at Buffalo, Buffalo, NY 14260-1300

4

5 Running title: MAPK Pathway Regulates Bud Emergence

7 Key Words: Rho GTPase, Cdc42p, polarity establishment, cell polarity, symmetry

8 breaking, bud emergence, MAPK, invasive growth, and pseudohyphal growth.

9 † Corresponding author: Paul J. Cullen

10 Address: Department of Biological Sciences 532 Cooke Hall

State University of New York at Buffalo

Buffalo, NY 14260-1300

Phone: (716)-645-4923

FAX: (716)-645-2975

e-mail: pjcullen@buffalo.edu

18 The manuscript contains 57 pages, 7 Figures, 2 Tables, 10 Supplemental Figures; 96,112

19 characters

Author contributions: A.P. designed experiments, generated data, and wrote the paper;

22 J.C. performed experiments and analyzed the data; A.J.S. performed experiments; P.J.C.

23 designed experiments and wrote the paper.

25 The authors have no competing interests in the study. 
MAPK Pathway Regulates Bud Emergence

Prabhakar et al.

\section{ABSTRACT}

27 All cells establish and maintain an axis of polarity that is critical for cell shape and

28 progression through the cell cycle. A well-studied example of polarity establishment is

29 bud emergence in yeast, where the Rho GTPase Cdc $42 p$ regulates symmetry breaking at

30 bud sites and the establishment of polarity by interacting with effector proteins. The

31 prevailing view of bud emergence does not account for regulation by extrinsic cues or

32 signal transduction pathways. Here, we show that the MAPK pathway that controls

33 filamentous growth (fMAPK pathway), which also requires Cdc42p and the effector p21

34 activated kinase (PAK) Ste20p, regulates bud emergence under nutrient-limiting

35 conditions that favor filamentous/invasive growth. The fMAPK pathway regulated the

36 expression of polarity targets that included the gene encoding a direct effector of Cdc42p,

37 Gic2p. The fMAPK pathway also stimulated GTP-Cdc42p levels, which is a critical

38 determinant of polarity establishment. The fMAPK pathway activity was spatially

39 restricted to bud sites and highest at a period in the cell cycle that coincided with bud

40 emergence. Time-lapse fluorescence microscopy showed that the fMAPK pathway

41 stimulated the rate of bud emergence during filamentous growth. Unregulated activation

42 of the fMAPK pathway induced growth at multiple sites that resulted from multiple

43 rounds of symmetry breaking inside the growing bud. Collectively, our findings identify

44 a new regulatory aspect of bud emergence that sensitizes this essential cellular process to

45 external cues. 
MAPK Pathway Regulates Bud Emergence

Prabhakar et al.

\section{INTRODUCTION}

48 All cells establish an axis of polarity, which is critical for cell shape, the organization of

49 cellular compartments, and progression through the cell cycle (Doerr and Ragkousi,

50 2019). Cell polarity can be reorganized in response to intrinsic and extrinsic cues and is

51 required during development and for other processes that require dynamic changes in cell

52 shape such as cell migration and differentiation (Henderson et al., 2018; Pei et al., 2019;

53 Piroli et al., 2019). Defects in cell polarity are commonly associated with human disease.

54 For example, the mis-regulation of cell polarity leads to metastasis in many types of

55 cancers (Noguchi et al., 2018; Taciak et al., 2018; Fomicheva et al., 2019).

Cdc42p and other members of the Rho family of GTPases are central regulators

57 of cell polarity (Pringle et al., 1995; Pruyne and Bretscher, 2000a, b; Irazoqui and Lew,

58 2004; Arkowitz and Iglesias, 2008; Zihni and Terry, 2015; Jimeno and Santos, 2017;

59 Woods and Lew, 2019). In yeast, Cdc42p regulates bud emergence, which is an essential

60 process where daughter cells or buds are produced from mother cells. The pathway that

61 regulates bud emergence has been extensively studied and represents one of the best

62 examples for how cells establish an axis of polarity (Fig. 1A, green pathway). Activation

63 of Cdc42p by the guanine nucleotide exchange factor (GEF) Cdc24p at bud sites - or at

64 random sites in bud-site-selection mutants - results in symmetry breaking, which

65 commits the cell to grow at a particular site. Positive and negative feedback loops

66 promote polarity establishment by amplifying the levels of active or GTP-bound Cdc42p

67 at the incipient bud site (Irazoqui et al., 2003; Kozubowski et al., 2008; Chiou et al.,

68 2018; Woods and Lew, 2019). The GTP-bound conformation of Cdc42p binds effector

69 proteins (Wu and Jiang, 2005; Wu et al., 2006; Yang et al., 2007; Guo et al., 2010; 
70 Bendezu and Martin, 2013; McCormack et al., 2013), including Gic1p and Gic2p (Brown

71 et al., 1997; Chen et al., 1997; Kawasaki et al., 2003; Iwase et al., 2006; Liu et al., 2019),

72 p21 activated kinases (PAKs) Ste20p and Cla4p (Cvrckova et al., 1995; Simon et al.,

73 1995; Gulli et al., 2000; Hofmann et al., 2004; Takahashi and Pryciak, 2007), and the

74 formin Bnilp (Evangelista et al., 1997; Sherer et al., 2018). In a highly choreographed

75 manner that is coordinated with the cell cycle (Moran et al., 2019), effector proteins

76 regulate the assembly of septin ring, which forms a diffusion barrier between mother and

77 daughter cells, and the formation of actin cables, which direct the delivery of vesicles to

78 the nascent bud site. In this way, buds are produced from mother cells in a precisely

79 spatially and temporally regulated manner.

$80 \quad \operatorname{Cdc} 42 \mathrm{p}$ also regulates mitogen activated protein kinase (MAPK) pathways

81 (Simon et al., 1995; Brown et al., 1996; Martin, 2019). MAPK pathways are

82 evolutionarily conserved signaling modules that control cell differentiation and the

83 response to stress in eukaryotes (Yoon and Seger, 2006; Raman et al., 2007; Dinsmore

84 and Soriano, 2018; Papa et al., 2019). In yeast, nutrient limitation induces a Cdc42p-

85 dependent MAPK pathway that regulates filamentous/invasive/pseudohyphal growth

86 [Fig. 1A, blue pathway, fMAPK pathway (Gimeno et al., 1992; Roberts and Fink, 1994;

87 Mosch et al., 1996; Peter et al., 1996; Leberer et al., 1997; Mosch et al., 1999; Pan et al.,

88 2000; Gancedo, 2001; Borneman et al., 2007; Adhikari et al., 2015; Cullen, 2015).

89 Filamentous growth occurs in many fungal species, and in some plant and animal

90 pathogens, filamentous growth is required for virulence (Lo et al., 1997; Desai et al.,

91 2014; Lagree and Mitchell, 2017). At the head of the fMAPK pathway, plasma-

92 membrane proteins Msb2p and Sholp regulate the Cdc42p module, which leads to the 
93 recruitment and activation of Ste20p, the specific $\mathrm{Cdc} 42 \mathrm{p}$ effector that regulates the

94 fMAPK pathway. Ste20p in turn induces a MAPK cascade composed of Ste11p

95 (MAPKKK), Ste7p (MAPKK), and Kss1p (MAPK) (Roberts and Fink, 1994; Madhani et

$96 a l ., 1997)$. The MAPK Kss1p regulates the activity of transcription factors Ste12p and

97 Tec1p, as well as transcriptional repressors and other factors (Madhani and Fink, 1997;

98 Bardwell et al., 1998; van der Felden et al., 2014) to regulate expression of target genes

99 that bring about the filamentous cell type (Rupp et al., 1999; Roberts et al., 2000).

100 Despite the fact that bud emergence is extensively regulated by positive and

101 negative feedback loops and is coordinated with the cell cycle, bud emergence is not

102 known to be regulated by extrinsic cues or signaling pathways. The fMAPK and polarity

103 pathways both require $\mathrm{Cdc} 42 \mathrm{p}$, which suggests that functional cross talk may occur

104 between the two pathways. In support of this possibility, we have recently found that

105 bud-site-selection proteins regulate the fMAPK pathway [Fig. 1A, green arrow, (Basu et

106 al., 2016)]. We tested the hypothesis that reciprocal cross talk might occur from the

107 fMAPK pathway to the bud emergence pathway (Fig. 1, blue arrow question mark), and

108 discovered a role for the fMAPK pathway in regulating bud emergence. An active

109 fMAPK pathway rescued the bud emergence defect of a polarity mutant (cdc24-4), and

110 was required for proper bud emergence during filamentous growth. The fMAPK pathway

111 accomplished this role by inducing expression of a direct effector of Cdc42p that

112 functions in budding (GIC2) and by directly stimulating GTP-Cdc42p levels. The activity

113 of fMAPK pathway was regulated during the cell cycle to peak prior to and during bud

114 emergence and when mis-regulated induced growth at multiple sites. Our study therefore

115 identifies a new regulatory facet of bud emergence that is subject to regulation by a 
bioRxiv preprint doi: https://doi.org/10.1101/786426; this version posted September 30, 2019. The copyright holder for this preprint (which was not certified by peer review) is the author/funder. All rights reserved. No reuse allowed without permission.

MAPK Pathway Regulates Bud Emergence

Prabhakar et al.

116 MAPK pathway and external cues. Given that Rho GTPases are functionally connected

117 to MAPK pathways in higher eukaryotes, it is likely that polarity establishment is more

118 likely to be subject to input from MAPK and other pathways than is currently

119 appreciated. 
MAPK Pathway Regulates Bud Emergence

Prabhakar et al.

\section{RESULTS}

121 fMAPK Pathway Rescues the Bud Emergence Defect of cdc24-4 Through Gic2p

122 MSB2 (Multicopy Suppressor of Budding Defect 2) was initially characterized as a high-

123 copy suppressor of the budding and growth defects of the $c d c 24-4$ mutant (Bender and

124 Pringle, 1989, 1992). Msb2p was subsequently identified as the mucin-type glycoprotein

125 that regulates the fMAPK pathway [Fig. 1A, blue pathway (Cullen et al., 2004)]. To

126 determine whether Msb2p regulates budding through the fMAPK pathway, plasmids

127 carrying alleles that hyper-activate the fMAPK pathway were introduced into the $c d c 24-4$

128 mutant and examined for growth at $37^{\circ} \mathrm{C}$. Hyperactive versions of Msb2p (pGFP-MSB2)

129 weakly suppressed the growth defect of the $c d c 24-4$ mutant (Fig. 1B). Hyperactive

130 versions of Sholp (pSHO1 $\left.{ }^{\mathrm{P} 20 \mathrm{~L}}\right)$ and Ste11p (pSTE11-4) more robustly rescued the

131 growth defect of the $c d c 24-4$ mutant (Fig. 1B). pSTE11-4 also rescued the polarity defect

132 of the $c d c 24-4$ mutant (Fig. S1A). Therefore, activated versions of MAPK pathway

133 components can rescue the growth and polarity defects of a bud emergence mutant.

134 Msb2p, Sho1p, and Ste11p regulate two MAPK pathways [fMAPK and HOG

135 (Saito, 2010)]. A pathway-specific regulator of the HOG pathway, Pbs2p (Brewster et al.,

136 1993; Zarrinpar et al., 2004; Nishimura et al., 2016), was not required for growth of the

$137 c d c 24-4$ mutant (Fig. 1C). In fact, the $c d c 24-4 \Delta p b s 2 \Delta$ double mutant grew better than

138 the $c d c 24-4$ single mutant, perhaps because the HOG pathway negatively regulates the

139 fMAPK pathway and its loss results in hyperactive fMAPK (Davenport et al., 1999). By

140 comparison, a pathway-specific regulator of the fMAPK pathway, Teclp (Madhani and

141 Fink, 1997) was required for viability of the $c d c 24-4$ mutant (Fig. 1B). Tec1p functions

142 with another transcription factor, Ste12p (Liu et al., 1993), which was also required for 
143 growth of $c d c 24-4$ (Fig. 1C). Ste11p and Ste12p also regulate the mating pathway, but

144 these experiments were carried out in a mating defective strain (ste4 $\Delta$ ). Tec1p was also

145 required for suppression of the growth defect of the $c d c 24-4$ mutant by pSTE11-4 (Fig.

146 1B). pSTE11-4 also induced phosphorylation of the MAP kinase for the fMAPK

147 pathway, Kss1p (P Kss1p) in the $c d c 24-4$ mutant (Fig. S1B). Therefore, the MAPK

148 pathway that controls filamentous/invasive growth regulates bud emergence in a defined 149 genetic context.

150 The fMAPK pathway controls filamentous growth by regulating target genes that

151 control cell adhesion [FLO11 (Rupp et al., 1999)], bud-site selection [BUD8 (Taheri et

152 al., 2000; Harkins et al., 2001; Cullen and Sprague, 2002)] and cell elongation [CLN1

153 (Kron et al., 1994; Loeb et al., 1999; Madhani et al., 1999)]. None of these genes were

154 required for viability of the $c d c 24-4$ mutant (Fig. S1C). To identify relevant polarity

155 targets of the fMAPK pathway, GO term analysis was performed on data generated in

156 (Chow et al., 2019). Polarity targets of the fMAPK pathway included genes that regulate

157 bud-site selection (Fig. S1D, AXL2, BUD8, RSR1 and RAX2), polarity establishment

158 (MSB2, GIC2, and RGA1), and septin ring organization (GIC2, AXL2, and RGA1). GIC2

159 in particular encodes a direct effector of Cdc42p that along with GICl functions in bud

160 emergence [Fig. 1A, (Brown et al., 1997; Chen et al., 1997)]. The GIC2 gene was a

161 target of the fMAPK pathway [Fig. S2A and see (MacIsaac et al., 2006)].

162 Gic2p was required for viability of the $c d c 24-4$ mutant [Fig. 1B, (Costanzo et al.,

163 2010)] and to suppress the growth defect of $c d c 24-4$ by pSTE1 1-4 (Fig. 1B). Expression

164 of GIC2 from a fMAPK pathway-independent promoter partly rescued the growth defect

165 of the $c d c 24-4$ mutant (Fig. 1B, pTEF2-GIC2) even in cells lacking an intact fMAPK 
166 pathway (pTEF2-GIC2 ste12A). Gic2p played a unique role compared to Gic1p (Fig. S2A

167 and $B$ ). Thus, Gic2p is a target of the fMAPK pathway required for fMAPK pathway-

168 dependent rescue of the $c d c 24-4$ mutant.

169 Gic proteins regulate clustering or polarization of Cdc42p at bud sites (Daniels et

170 al., 2018; Kang et al., 2018), which is a critical step in polarity establishment. Time-lapse

171 fluorescence microscopy showed that GFP-Cdc42p clustered at a specific site on the cell

172 cortex (Fig. 1D, wild type, asterisk), from which site new buds emerged. The cdc24-4

173 mutant was defective for GFP-Cdc42p clustering and bud emergence (Fig. 1D, cdc24-4).

174 Analysis of 30 cells showed this difference to be statistically significant (Fig. 1E).

$175 \mathrm{pSTE} 11-4$ partially restored GFP-Cdc42p clustering and bud emergence to the $c d c 24-4$

176 mutant (Fig. 1, D and E). Rescue of bud emergence by pSTE11-4 was dependent on

177 Gic2p (Fig. 1, D and E).

178 During bud emergence, Gic proteins also regulate formation of the septin ring

179 (Iwase et al., 2006; Bi and Park, 2012; Okada et al., 2013; Sadian et al., 2013; Kang et

180 al., 2018). In wild-type cells, the septin Cdc12p-GFP was localized in a ring prior to bud

181 emergence (Fig. 1F, arrows) and to the mother-bud neck in budding cells (Fig. 1F,

182 asterisk). In the $c d c 24-4$ mutant, Cdc12p-GFP showed a punctate pattern on the cell

183 cortex (Fig. 1F, red arrows). Based on the analysis of over 150 cells, the localization

184 defect was statistically significant (Fig. 1F). pSTE11-4 partially rescued the septin

185 localization defect of the $c d c 24-4$ mutant (Fig. 1, F and $\mathbf{G}$ ), which was dependent on

186 Gic2p (Fig. 1, F and G). The fMAPK pathway did not suppress the growth defect of the

187 cdc12-6 mutant, which indicates that it functions upstream of the septins themselves (Fig.

188 S2C). Gic2p also promotes the interaction between Cdc42p and Bnilp (Chen et al., 
191 Bnilp is required for septin ring assembly (Kadota et al., 2004; Gladfelter et al., 2005).

192 In wild-type cells Gic2p was required for invasive growth (PWA, Fig. S3A), colony

193 ruffling (Fig. S3B), and septin organization (Fig. S3C-E) of filamentous cells. Gic2p did

194 not regulate the fMAPK pathway (Fig. $S 3 F)$. These results establish a new role for the

195 fMAPK pathway in regulating bud emergence by a mechanism that involves Gic2p.

\section{The fMAPK Pathway Regulates GTP-Cdc42p Levels During Filamentous Growth}

198 Like other monomeric GTPases, the exchange of GDP for GTP alters the conformation of

199 the protein and allows the protein to bind effector proteins. During budding, the increase

200 in GTP-Cdc42p levels is critical for symmetry breaking and polarity establishment

201 (Irazoqui et al., 2003; Kozubowski et al., 2008). Msb2p interacts with GTP-Cdc42p to

202 activate the fMAPK pathway (Cullen et al., 2004) and during filamentous growth, the

203 level and activity of Msb2p is stimulated by positive feedback (Fig. S1D). To test

204 whether Msb2p and the fMAPK pathway impacts the levels of GTP-Cdc42p in the cell, a

205 fluorescent reporter that measures GTP-Cdc42p levels was examined [Gic2p-PBD-

206 tdTomato (Okada et al., 2013)]. Compared to cells undergoing yeast-form growth

207 (YEPD), cells undergoing filamentous growth showed elevated levels of GTP-Cdc42p

208 (Fig. 2A; YEP-GAL). The increase in GTP-Cdc42p levels was dependent on the fMAPK 209 pathway (Fig. 2A) in a manner that was statistically significant (Fig. 2B, YEP-GAL; p-

210 value $<0.00001$ ). As previously shown (Okada et al., 2013), the level of GTP-Cdc42p 
211 was also higher in cells responding to the mating pheromone $\alpha$-factor (Fig. 2, A and B).

212 In this case, the increase was independent of the fMAPK pathway.

214 by its endogenous promoter, which, as shown above is regulated by the fMAPK pathway.

215 As a separate test, the activity of a Cdc42p biosensor (Smith et al., 2013) was examined

216 by fluorescence lifetime imaging [FLIM-FRET (Sun et al., 2011)]. In wild-type cells, the

217 Cdc42p biosensor exhibited shorter lifetimes with a version that mimics the GTP-bound

218 conformation (Fig. 2C, Cdc42 $\mathrm{p}^{\text {Q61L }}$ ) and longer lifetimes with a version that mimics the

219 GDP-bound conformation (Fig. 2C, Cdc42 $\mathrm{p}^{\mathrm{D} 57 \mathrm{Y}}$ ). Activation of the fMAPK pathway

220 reduced the lifetime of the biosensor (Fig. 2C, $M S B 2^{\Delta 100-818}$ ). This change corresponded

221 to a $25 \%$ increase in the total levels of GTP-Cdc $42 \mathrm{p}$, which has previously been shown to

222 reflect changes in Cdc42p activity during bud emergence (Smith et al., 2013). Cdc42p

223 activity can also be impacted by the Gic proteins (Kawasaki et al., 2003; Daniels et al.,

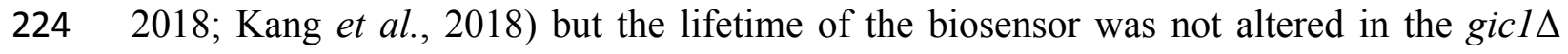

225 gic $2 \Delta$ double mutant (Fig. 2C). Hyperactive versions of Msb2p, Sho1p, and Ste11p also

226 partially suppressed the growth defect of the gicl $\Delta$ gic $2 \Delta$ double mutant at $37^{\circ} \mathrm{C}[$ Fig. S4,

227 (Gandhi et al., 2006)] which supports a role for fMAPK in regulating bud emergence that

228 is separate from Gic protein function.

230 fMAPK Pathway Is Temporally and Spatially Regulated to Coincide with Bud

231 Emergence Bud emergence occurs in the $\mathrm{G}_{1}$ phase of the cell cycle (Hartwell et al.,

232 1970; Lew and Reed, 1993; Pringle et al., 1995; Gulli et al., 2000; Howell and Lew, 233 2012; Moran et al., 2019). Whether the fMAPK pathway is active in the $\mathrm{G}_{1}$ phase of the 
234 cell cycle has not been explored. To address this question, cells were synchronized in the

$235 \mathrm{G}_{1}$ phase of the cell cycle by $\alpha$-factor (Breeden, 1997), and fMAPK pathway activity was

236 assessed under basal (YEPD) and activating conditions (YEP-GAL) as cells progressed

237 through the cell cycle. An epitope-tagged cyclin, Clb2p-HA, showed the expected pattern

238 of cell-cycle regulation (Richardson et al., 1992; Irniger et al., 1995; Wasch and Cross,

239 2002; Cross et al., 2005; Eluere et al., 2007; Kuczera et al., 2010; Cepeda-Garcia, 2017),

240 increasing after $\alpha$-factor release by $60 \mathrm{~min}$ and decreasing by $90 \mathrm{~min}$ as cells entered

241 anaphase (Fig. 3A, $\alpha$-HA). P Kss1p levels also increased after $\alpha$-factor release by 80 min

242 and peaked by $100 \min$ (Fig. 3A; P Kss1p). By comparison, the level of P Fus3p, which

243 is the MAP kinase that regulates the mating pathway, decreased after release from $\alpha$ -

244 factor (Fig. 3A; P Fus3p). Conditions that activate the fMAPK pathway (YEP-GAL) led

245 to a delay in Clb2p-HA accumulation (Leitao and Kellogg, 2017) and also showed an

246 increase in $\mathrm{P} \sim \mathrm{Kss} 1 \mathrm{p}$ levels in the $\mathrm{G}_{2} / \mathrm{M}$ phase of the cell cycle, prior to next round of bud

247 emergence (Fig. 3B). These results demonstrate that the activity of the fMAPK pathway

248 is cell-cycle regulated and increases prior to and during bud emergence.

249 Bud emergence is spatially regulated in that it results from Cdc42p activation at

250 bud sites (Caviston et al., 2003; Das et al., 2007; Freisinger et al., 2013; Okada et al.,

251 2013). We previously showed that bud-site-selection proteins regulate the fMAPK

252 pathway (Basu et al., 2016), which indicates that the fMAPK pathway is active at sites

253 where bud emergence occurs. In line with this possibility, key regulators of the fMAPK

254 pathway, including Sho1 (see below) and Ste20p are recruited to bud sites prior to bud

255 initiation (Moran et al., 2019). Moreover, polarity targets of the fMAPK pathway

256 included proteins that promote budding at bud sites (Fig. S1D). Polarity targets also 
257 included proteins that prevent budding at previous division sites or cytokinesis remnants.

258 These included Rgalp (Fig. S1D), which along with other GTPase activating proteins

259 (GAPs) prevents budding within the existing growth site (Kadota et al., 2004; Tong et al.,

260 2007; Miller et al., 2017), and Rax2p (Fig. S1D), which restricts budding at previous

261 division sites in a complex with Raxlp, Gpslp, Nbalp and Nis1p (Meitinger et al.,

262 2014). Rgalp has been shown to negatively regulate the fMAPK pathway (Smith et al.,

263 2002). Cells lacking Rax2p, Nba1p, or Gps1p also showed elevated fMAPK pathway

264 activity (Fig. 3C, Fig. S5A), which indicates that the negative polarity complex

265 negatively regulates the fMAPK pathway. The elevated activity of the fMAPK pathway

266 in negative polarity complex mutants also required Msb2p (Fig. 3D, Fig. S5A-B). Cells

267 lacking the negative polarity complex did not impact mating (Fig. S5C). Therefore,

268 proteins that spatially promote budding promote fMAPK activity, and proteins that

269 spatially restrict budding also restrict fMAPK pathway activity. Collectively, the data

270 indicate that fMAPK pathway activity is temporally and spatially regulated to coincide

271 with bud emergence.

\section{fMAPK Pathway Stimulates the Rate of Bud Emergence During Filamentous Growth}

274 To further define how the fMAPK regulates bud emergence, the timing of bud emergence

275 was examined using a septin marker (Cdc3p-mCherry) that shows a characteristic

276 localization pattern throughout the cell cycle (Kim et al., 1991; Lippincott et al., 2001).

277 In yeast-form cells grown in SD-URA (GLU), the timing of GFP-Cdc42p clustering,

278 septin recruitment by Cdc3p-mCherry, and bud emergence were similar between wild-

279 type cells and an fMAPK pathway mutant (Fig. S6A). In filamentous wild-type cells 
28110 min [Fig. 4; A (green arrowheads) and B; Movie 1; Fig. S7A] from the preceding

282 round of cytokinesis marked by the septin hourglass split into double ring [(Fig. $\mathbf{4 A}$, set

283 as $\mathrm{t}=0$ ) (Cid et al., 2001; Lippincott et al., 2001)]. The recruitment of Cdc3p-mCherry

284 had also occurred within this duration [Fig. 4; A (red arrowheads) and B; Movie 1; Fig.

$285 S 7 A$ ). The average time for bud emergence for 17 wild-type cells was recorded as 30

286 minutes from the preceding cytokinesis (Fig. 4B). Strikingly, in the fMAPK pathway

287 mutant grown under filamentous conditions (GAL), delay in GFP-Cdc42p clustering,

288 Cdc3p-mCherry recruitment and bud emergence were observed (Fig. 4B). For a given

289 fMAPK mutant cell, initial GFP-Cdc42p clustering and Cdc3p-mCherry recruitment

290 occurred within the same time span [(Fig. 4, B and C (example 1, green and red

291 arrowheads)]. However, some cells showed disappearance and reappearance of the GFP-

292 Cdc42p cluster at the initial polarity site [(Fig. 4C and D (oscillation seen in the pixel

293 intensity graphs); Movie 2-4; Fig. $S 7 B-D]$. The disappearance and reappearance of the

294 GFP-Cdc42p cluster, referred here as transient disappearance of polarity complex,

295 accounted for a significant delay in bud emergence in the fMAPK pathway mutant (Fig.

296 4, B and C). Some of these cells even failed to make buds within the time of the

297 experiment (Fig. 4D; Movie 3-4; Fig. S7C-D). In other examples, the initial polarity site

298 disappeared and reappeared at a new site from where the bud came out [Fig. 4E (in the

299 mother cell, compare the location of green and red arrowhead with the black arrow that

300 marks bud emergence); Movie 5-6; Fig. S7E-F]. The transient disappearance of the

301 polarity complex, seen at some level in wild-type cells (although they always made a

302 bud), was increased by 3-fold in the fMAPK mutant (Fig. 4F). Representing GFP- 
303 Cdc42p intensity in each cell as the coefficient of variation (CV) of pixel intensity (Lai et

$304 a l ., 2018$ ) over time brought out the polarity defect in the fMAPK mutant relative to the

305 wild type (Fig. 4G). The coefficient of variation (CV) of pixel intensity also showed a

306 larger change in wild type $(0.16$ to $0.23=7)$ compared to the ste $12 \Delta$ mutant $(0.14$ to 0.18

$307=4$ ), which was statistically significant ( $p$-value, $<0.01$ ). These results define a function

308 for the fMAPK pathway in stimulating the rate of bud emergence under conditions that

309 promote filamentous growth.

310 To look at active Cdc42p during bud emergence in filamentous conditions, Gic2p-

311 PBD-tdTomato reporter was co-localized with Sholp-GFP, an fMAPK pathway regulator

312 which is a direct effector of Msb2p (Cullen et al., 2004; Tatebayashi et al., 2007) that

313 interacts with Cdc24p (Vadaie et al., 2008), Ste20p, and Ste11p (Zarrinpar et al., 2004;

314 Tatebayashi et al., 2006). Although Sholp is known to localize to polarized sites

315 (Pitoniak et al., 2009), its localization throughout the cell cycle has not been explored. In

316 wild-type cells, Sho1p-GFP was localized to incipient bud sites prior to bud emergence

317 together with GTP-Cdc42p (Fig. S6B-C; wild type; red arrow). After bud emergence,

318 Sho1p-GFP was found at the bud tips as has been reported (Pitoniak et al., 2009). In

319 tec1s mutant cells, Sholp-GFP initially localized to the incipient bud site but failed to

320 become enriched, and instead migrated back and forth along the distal pole (Fig. S6C;

321 tec $1 \Delta$; black arrows). The low level of active Cdc42p in these cells rapidly disappeared.

322 Bud formation was delayed and in the cell shown bud emergence did not occur within the

323 time of the experiment. Thus, although, active Cdc42p clusters at incipient bud sites, an

324 intact fMAPK pathway is required to promote bud emergence under nutrient limiting

325 conditions. Cells lacking the fMAPK pathway showed a growth defect under filamentous 
326 conditions (Fig. S6D, GAL) and a defect in the rate of bud formation (Fig. S6, E, and F).

327 In particular, at $5 \mathrm{~h}, 10 \mathrm{~h}$, and $18 \mathrm{~h}$, the ste $12 \Delta$ mutant formed buds at a slower rate than

328 wild-type cells. Therefore, the fMAPK pathway stimulates the rate of budding during

329 filamentous growth.

331 Activation of the fMAPK Pathway Induces Growth at Multiple Sites

332 Wild-type cells normally grow at a single site due to a regulatory phenomenon known as

333 singularity in budding. Cells containing active versions of Cdc42p bypass this regulation

334 and grow at multiple sites (Richman and Johnson, 2000; Caviston et al., 2002; Wedlich-

335 Soldner et al., 2003; Wedlich-Soldner et al., 2004; Howell et al., 2009; Howell et al.,

336 2012). Cells containing hyperactive versions of Msb2p also had this property [Fig. 5A,

337 (Basu et al., 2016)]. Further inspection showed that $16 \%$ of cells carrying $M S B 2^{\Delta 100-818}$

338 showed multiple growth sites (Fig. 5B, $M S B 2^{\Delta 100-818}$ ). Given that the fMAPK pathway

339 regulates bud emergence, the ability of $\mathrm{Msb} 2 \mathrm{p}$ to induce multiple growth sites might be

340 mediated by the fMAPK pathway. We found that the formation of multiple growth sites

341 by $M S B 2^{\Delta 100-818}$ required the fMAPK pathway (Fig. 5B, $M S B 2^{\Delta 100-818}$ ste $12 \Delta$ ). Growth at

342 multiple sites was also induced by STE11-4 or overexpression of SHO1 (Fig. 5B). The

343 formation of multiple growth sites correlated with fMAPK pathway activity (Fig. 5, B

344 and C). The activity of the fMAPK pathway is stimulated by positive feedback, which is

345 evident by immunoblot of the Kss1p protein (Fig. 5C, middle blot), whose levels are

346 controlled by the fMAPK pathway (Roberts et al., 2000). Thus, Msb2p might itself

347 induce multiple growth sites but require the fMAPK pathway for positive feedback.

348 However, this was not the case. $M S B 2^{\Delta 100-818}$ expressed from an inducible promoter 
$349(p G A L)$ that did not depend on the fMAPK pathway also required Ste12p to form

350 multiple growth sites (Fig. 5, B and C, compare GAL-MSB2 $2^{\Delta 100-818}$ to $G A L-M S B 2^{\Delta 100-818}$

351 ste12 $\Delta$ ). Therefore, Msb2p activation itself is not sufficient to induce growth at multiple

352 sites. The fact that $M S B 2^{\Delta 100-818}$ is more effective at inducing growth at multiple sites

353 than STE11-4 can be explained by fMAPK pathway activity.

354 Transcriptional targets of the fMAPK pathway may be required for the formation

355 of multiple growth sites. Bnilp and Gic2p were required for multiple growth site

356 formation by the fMAPK pathway (Fig. 5D). High-copy expression of GIC2 itself

357 induced multiple growth sites (Fig. 5D), in line with a previous report (Jaquenoud et al.,

358 1998). The negative polarity complex did not impact growth at multiple sites (Fig. 5B,

359 pSTE11-4 nbal $\Delta$ ), although it did stimulate the fMAPK pathway activity (Fig. 5C).

360 Collectively, these results support a role for the fMAPK pathway in the regulation of bud

361 emergence, because activation of the fMAPK pathway can induce growth at multiple

362 sites.

\section{The fMAPK Pathway Induces Symmetry Breaking in the Growing Bud}

365 The multiple growth sites produced by the fMAPK pathway differed in shape from

366 previous reports on multiple bud formation by hyper-activation of Cdc $42 \mathrm{p}$ (Caviston et

367 al., 2002; Wedlich-Soldner et al., 2003; Wedlich-Soldner et al., 2004). Hyperactive

368 Cdc42p induces symmetry breaking in the mother cell to trigger formation of a second

369 bud. By comparison, the hyperactive fMAPK pathway did not impact budding in mother

370 cells. The multiple growth sites were formed inside the growing bud (Fig. 6A). To our

371 knowledge, this new phenotype has not been previously characterized. Growth at a 
372 second site within the growing bud was not due to abortive growth at the initial site,

373 because polarity proteins including Cdc24p-GFP (Fig. 6B) and F-actin (Fig. 6C, Fig.

$374 S 8 A-B)$ localized to multiple sites. Cells expressing $M S B 2^{\Delta 100-818}$ showed asymmetric

375 clustering of GFP-Cdc42p (Fig. 6D, Movie 8, Fig. S9B). Over time, GFP-Cdc42p

376 migrated along the bud cortex (Fig. 6D), which was evident by kymograph analysis (Fig.

377 6E), which allows tracking of changes in protein localization over time (Kaksonen et al.,

378 2003). Sec3p-GFP localization corroborated that these sites were actively growing (Fig.

$379 S 8 B$ ). Some wandering of GFP-Cdc42p occurred in wild-type cells (Movie 7, Fig. S9A),

380 which might be due to the off-center delivery of vesicles that dilute the polarity complex

381 (Dyer et al., 2013; Chiou et al., 2017).

382 The hyperactive fMAPK pathway may alter the dynamics of the interaction

383 between $\mathrm{Cdc} 42 \mathrm{p}$ and its effectors in a manner that makes the Cdc42p polarity axis

384 'forget' its orientation. This may mimic symmetry breaking occurring but within the bud

385 cortex. In line with this possibility, versions of Cdc42p that contain point mutations in the

386 effector-binding domain (such as Cdc42 $\mathrm{p}^{\mathrm{V} 36 \mathrm{~T}}$ ), which impair its interaction with effector

387 proteins (Gladfelter et al., 2001; Gladfelter et al., 2002; Gladfelter et al., 2005), showed a

388 similar phenotype (Fig. 6F). Here multiple protrusions occurred adjacent to the previous

389 polarization site. Similarly, cells expressing $M S B 2^{\Delta 100-818}$ formed multiple growth

390 projections (Fig. 6A, three, four, or five sites). Other genes can induce multiple buds

391 when overexpressed (Sopko et al., 2006), but these did not rescue the growth defect of

392 the $c d c 24-4$ mutant and in most cases worsened it (Fig. S10). These results demonstrate

393 the importance of a properly regulated fMAPK pathway in bud morphogenesis. 
MAPK Pathway Regulates Bud Emergence

Prabhakar et al.

\section{DISCUSSION}

396 Here we show that bud emergence, which is one the most intensively studied and well

397 understood polarity establishment processes in eukaryotes, is regulated by a MAPK

398 pathway. The fMAPK pathway regulates transcription of polarity target genes and GTP-

399 Cdc42p levels to increase the rate of bud emergence during filamentous growth. In this

400 way, bud emergence is regulated by a pathway whose activity is sensitive to extrinsic

401 cues. Importantly, the ability of the fMAPK pathway to induce the expression of polarity

402 target genes allows the pathway to tailor bud emergence by altering the levels of proteins

403 that act at multiple steps in the polarity pathway.

404 The fMAPK pathway may also regulate bud emergence during vegetative growth.

405 Ste20p is the first effector recruited by Cdc42p at bud sites (Moran et al., 2019), which is

406 known to activate the fMAPK pathway at bud sites to regulate bud emergence. Ste12p

407 and Tec1p are also required for viability of the $c d c 24-4$ mutant under vegetative growth

408 conditions. A function for the fMAPK pathway in regulating bud emergence might be

409 masked by genetic buffering under normal growth conditions. Indeed, cells lacking TEC1

410 are synthetically lethal with a diverse class of cytoskeletal and cell-cycle regulatory genes

411 (Costanzo et al., 2010). More recently, Rsr1p in its GDP-locked state has been shown to

412 regulates the timing of Cdc42p polarization in the early $\mathrm{G}_{1}$ by interaction with Bem1p

413 (Miller et al., 2019). Rsr1p (Basu et al., 2016) and Bem1p (Basu et al., UNDER

414 REVIEW) both regulate the fMAPK pathway.

415 A key polarity target of the fMAPK pathway is Gic2p, which is a direct effector

416 of Cdc42p that controls multiple steps in bud emergence. The regulation of GIC2

417 expression may be a key step in the regulation of polarity establishment in general. GIC2

418 expression is regulated by the fMAPK pathway and other proteins that regulate 
419 filamentous growth, including Phd1p (Gimeno and Fink, 1994; MacIsaac et al., 2006),

420 Rim101p (Lamb and Mitchell, 2003; Hu et al., 2007), SAGA (Venters et al., 2011) and

$421 \mathrm{Rpd} 3 \mathrm{p}(\mathrm{L})$ (Hu et al., 2007; Venters et al., 2011). GIC2 expression is also regulated

422 during mating (Roberts et al., 2000) and the Gic proteins are required for shmoo

423 formation (Brown et al., 1997). Gic2p may function in other contexts as well, and has

424 been implicated as an effector of the Protein Kinase C pathway (Zanelli and Valentini, 425 2005). Generally speaking, changes in gene expression may impact the regulation of bud 426 emergence during cell differentiation and the response to stress.

427 Here and in Basu et al. (2016) we identify cross talk between the polarity pathway

428 and the fMAPK pathway that impacts bud emergence and filamentous growth (Fig. 7).

429 One new connection is that transcriptional amplification of fMAPK pathway target genes

430 by positive feedback stimulates GTP-Cdc42p levels. A second connection is that bud-

431 site-selection proteins that regulate the fMAPK pathway may reinforce bud emergence at 432 bud sites, potentially by altering the expression of polarity target genes. A third 433 connection is that the fMAPK pathway induces target genes that prevent growth and

434 MAPK signaling at dormant growth sites (Meitinger et al., 2013). Such cross talk reveals

435 the precision that is required for proper bud emergence. Too little fMAPK pathway 436 activity causes a delay in bud emergence during filamentous growth, and too much leads 437 to growth at multiple sites. Precise regulation of the fMAPK pathway comes from 438 activation at the right place (incipient bud sites) and time (at $M / G_{1}$ ). The fact that the 439 fMAPK pathway is cell-cycle regulated is a novel finding. Cell-cycle regulation of the 440 fMAPK pathway might occur through TEC1, which like other $\mathrm{G}_{1}$ specific genes in the 441 'SIC' cluster (Cho et al., 1998; Spellman et al., 1998; Wittenberg and Reed, 2005) is 
442 induced at the $\mathrm{M} / \mathrm{G}_{1}$ boundary by the cell-cycle regulated transcription factor Swi5p

443 (Spellman et al., 1998).

444 During vegetative growth in S. cerevisiae, Cdc42p-dependent budding is dictated

445 by bud-site-selection proteins (Chiou et al., 2017). In other fungal species, diverse

446 mechanisms of growth control predominate. In Schizosaccharomyces pombe, growth at

447 the two poles is maintained by regulated oscillations in Cdc42p activity (Das et al.,

448 2012). Changes in the orientation of the polarity complex occurs during mating (Nern and

449 Arkowitz, 2000; Dyer et al., 2013) and filamentous growth (this study) and may be a

450 common feature of fungal cell differentiation. In the filamentous fungus Ashbya gossypii,

451 Rsr1p regulates symmetric growth cone formation at the hyphal tip (Bauer et al., 2004).

452 In the major human fungal pathogen Candida albicans, Rsrlp and Cdc42p are also

453 required for proper hyphal growth (Si et al., 2016). MAPK pathways may be critical

454 regulators of $\mathrm{Cdc} 42 \mathrm{p}$-dependent morphogenesis during hyphal/pseudohyphal growth.

455 Parallels can also be drawn to higher eukaryotes. In mammals, the ERK pathway is

456 directly involved in breaking radial symmetry of spreading RAT2 fibroblast cells

457 (Klimova et al., 2016). In this case, ERK spatially restricts p190A-RhoGAP activity to

458 limit growth at the cell rear. Therefore, functional crosstalk between MAPK pathways

459 and Rho GTPases may constitute an underexplored regulatory circuit in many systems.

\section{MATERIALS AND METHODS}

462

\section{Strains and Plasmids}


464 Yeast strains are described in Table 1. Plasmids are listed in Table 2. Gene disruptions and

465 GAL1 promoter fusions were made by PCR-based methods (Baudin et al., 1993; Longtine

466 et al., 1998). Some gene disruptions were made with antibiotic resistance markers

467 KanMX6 (Longtine et al., 1998), HYG and NAT (Goldstein and McCusker, 1999). Internal

468 epitope fusions were made by the pop-in pop-out strategy (Schneider et al., 1995). Some

469 strains were made $u r a 3$ - by selection on 5-fluoroorotic acid (5-FOA). Gene disruptions

470 were confirmed by polymerase chain reaction (PCR) Southern analysis and confirmed by

471 phenotype when applicable.

472 The pRS series of plasmids (pRS315 and pRS316) have been described (Sikorski

473 and Hieter, 1989). To construct $c d c 24-4$ mutant (PC6936), NAT cassette in PC6077 was

474 replaced with URA3 using pop-in pop-out strategy (Schneider et al., 1995). Following

475 complimentary primers $\quad$ were $\quad$ used-

476 CAGAAGAGTACCATTGCTGTTATCATTTGTTGCCTAGCCCTATCAACTAAAGG

477 GAACAAAAGCTGG3' ${ }^{\prime}$ and

478 CAATATAATGGGTATAGCTTGAACATCTGCCCCTCTCTATCTAATGTCACTAT

479 AGGGCGAATTGG3'. Strain was subsequently made ura3s by selection on 5-

480 fluoroorotic acid (5-FOA). $c d c 24 \Delta$ was confirmed by phenotypic analysis. Msb2p

481 [pGFP-MSB2 (Adhikari et al., 2015)], Sho1p [pRS316-SHO1 ${ }^{D 16 H, P 120 L}-G F P$, or

482 SHO1 ${ }^{\text {P120L }}$ (Vadaie et al., 2008)], and Ste11p [YCp50-STE11-4 (Stevenson et al., 1992)],

483 have been described. Plasmid pRS316-SHO1-GFP has been described (Marles et al.,

484 2004) and was provided by Dr. Alan Davidson (University of Toronto, Ontario CA). In

$485 \mathrm{SHOl}^{\mathrm{D} 16 \mathrm{H}}$, the D16H mutation alone does not hyperactivate the fMAPK pathway, but

486 together with $\mathrm{P} 120 \mathrm{~L}$ mutation results in a hyperactive version of the protein. 
MAPK Pathway Regulates Bud Emergence

Prabhakar et al.

487 Overexpression constructs came from an ordered collection (Gelperin et al., 2005).

488 YEp352-TEF2-GIC2 was created by amplifying the GIC2 open reading frame (ORF) by 489 PCR from genomic DNA using complimentary primers pairs

490 5'GACTCTAGAATGACTAGTGCAAGTATTACCAATACTGGAAACG3' and

491 5'CAGtgtCGACTtAagtTtGCAGGGGCTCGAGC3'. The PCR product was

492 digested with XbaI and SalI and inserted into the YEp352-TEF2 plasmid (Pitoniak et al.,

493 2015) digested with the same enzymes. Positive clones were confirmed by DNA

494 sequencing.

495 Plasmid YCplac181-CDC12-GFP::KanMX6 was constructed from YCplac181-

496 CDC12-GFP (PC1365), provided by J. Pringle (Fares et al., 1996), by homologous

497 recombination. The KanMX6 cassette was amplified by PCR with flanking sequences to

498 LEU2 locus on the YCplac181-CDC12-GFP plasmid. Complimentary primers were

499 designed 5'-

500 ATGTCTGCCCCTAAGAAGATCGTCGTTTTGCCAGGTGACCACGTTGCGGATCC

501 CCGGGTTAATTA-3' and 5'-

502 TTAAGCAAGGATTTTCTTAACTTCTTCGGCGACAGCATCACCGACTGAATTCG

503 AGCTCGTTTAAAC -3' (Millipore Sigma, St. Louis, MO). The PCR product was co-

504 transformed with YCplac181-CDC12-GFP digested with AflII to target integration at the

505 LEU2 locus. Plasmids were rescued from isolates that were KanMX6 positive.

506 YCplac181-CDC12-GFP::NAT was made by the same strategy.

507 pRS316-GFP-CDC42::KanMX6 was made from pRS316-GFP-CDC42 (PC6454)

508 by targeting integration at the URA3 locus using complimentary primers 5'-

509 ATGTCGAAAGCTACATATAAGGAACGTGCTGCTACTCATCCTAGTCGGATCC 
511 TTAGTTTTGCTGGCCGCATCTTCTCAAATATGCTTCCCAGCCTGGAATTCGAG

512 CTCGTTTAAAC-3' (Millipore Sigma, St. Louis, MO). pRS316-pACT1-EGFP-

513 CRIBCLA4-CDC42 $2^{\triangle \mathrm{CAAX}}$-mCherry-CAAX::KanMX6 was made from pRS316-pACT1-

514 EGFP-CRIBCLA4-CDC42 ${ }^{\triangle \mathrm{CAAX}}$-mCherry-CAAX (PC7137) (Smith et al., 2013) and

$515 \mathrm{pSHO1}{ }^{\mathrm{D} 16 \mathrm{H}}-G F P:$ KanMX6 was made from $\mathrm{pSHOl}{ }^{\mathrm{D} 16 \mathrm{H}}-G F P$ (PC1964) by targeting

516 integration at the URA3 locus using same complimentary primers as for pRS316-GFP-

517 CDC42::KanMX6. The PCR product was co-transformed with plasmids digested with

518 BsmI to target integration at the URA3 locus. Plasmids were rescued from isolates that

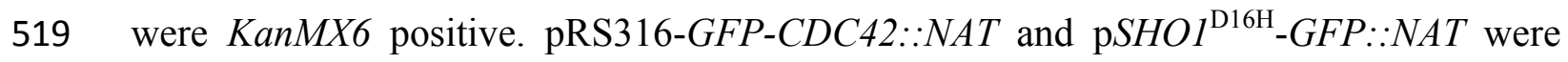

520 made by the same strategy.

521 Plasmids were recovered from cells with Promega Wizard Plus SV Miniprep

522 DNA Purification system (A1460, Promega, Madison, WI) used as specified by the

523 manufacturer with following modification. $100 \mu \mathrm{l}$ of glass beads were added at the lysis

524 step, and cells were vortexed for $5 \mathrm{~min}$ before the addition of neutralization buffer.

525 Rescued plasmids were transformed into E. coli, and positive clones were confirmed by

526 DNA sequencing, by GENEWIZ (South Plainfield, NJ) and by fluorescence microscopy

527 after transformation in yeast.

$529 \quad$ Filamentous Growth and Mating Assays

530 Yeast and bacterial strains were manipulated by standard methods (Sambrook, 1989;

531 Rose, 1990). The single cell invasive growth assay (Cullen and Sprague, 2000) and the

532 plate-washing assay (Roberts and Fink, 1994) were performed as described. Actin 
533 staining by rhodamine phalloidin was performed as described (Yuzyuk and Amberg,

534 2003). In cells lacking an intact mating pathway (ste4A), the FUS1-HIS3 reporter

535 (McCaffrey et al., 1987) was used to evaluate fMAPK pathway activity (Cullen et al.,

536 2004). FUS1-HIS3 activity was measured by spotting equal concentrations of cells onto

537 SD-HIS medium and SD-HIS medium containing 3-Amino-1,2,4-triazole (3-ATA).

538 Halo assays were performed as described (Jenness et al., 1987). A saturated

539 culture of cells $\left(\mathrm{A}_{600}=0.1\right)$ was spread on YEPD media and allowed to dry. $3 \mu \mathrm{l}$ and 10

$540 \mu \mathrm{l} \alpha$ - factor $(1 \mathrm{mg} / \mathrm{ml})$ were spotted on the plate. Plates were incubated at $30^{\circ} \mathrm{C}$ and

541 photographed at $24 \mathrm{~h}$ and $48 \mathrm{~h}$. Experiments were performed in triplicate. Halo diameter

542 (in $\mathrm{cm}$ ) was measured by ImageJ analysis and plotted as a function of $\alpha$-factor

543 concentration. For Lat-A sensitivity, saturated culture of cells $\left(\mathrm{A}_{600}=0.1\right)$ was spread

544 onto SD-URA-LEU media containing $0.5 \mathrm{M}$ sorbitol. $10 \mu \mathrm{l}$ of Lat-A (Sigma, L5163) at 0

545 (10 mM DMSO) $0.1 \mathrm{mM}, 0.2 \mathrm{mM}$ and $0.5 \mathrm{mM}$ (in $10 \mathrm{mM}$ DMSO) were spotted on

546 plates. Halo diameter (in $\mathrm{cm}$ ) was measured by ImageJ analysis and plotted as a function

547 of Lat-A concentration.

548

549 Evaluating MAP Kinase Phosphorylation by Immunoblot Analysis

550 Immunoblot analysis was used to detect phosphorylated MAP kinases as described

551 (Sabbagh et al., 2001; Lee and Dohlman, 2008; Basu et al., 2016). In cdc24-4 mutant

552 combinations, cells were grown to mid-log in $10 \mathrm{ml} \mathrm{SD-URA}$ at $30^{\circ} \mathrm{C}$ and then incubated

553 at $37^{\circ} \mathrm{C}$ for $4 \mathrm{~h}$. Cells were harvested by centrifugation. Pellets were washed once with

554 water and flash frozen in liquid nitrogen. In experiments that did not involve $c d c 24-4$, 555 cells were grown in YEPD or YEP-GAL media for the times incubated. Proteins were 
MAPK Pathway Regulates Bud Emergence

Prabhakar et al.

556 precipitated by trichloroacetic acid (TCA) and analyzed by sodium dodecyl sulfate

557 polyacrylamide gel electrophoresis (SDS-PAGE) (10\% acrylamide). Proteins were

558 transferred to nitrocellulose membranes (Amersham ${ }^{\mathrm{TM}}$ Protran $^{\mathrm{TM}}$ Premium $0.45 \mu \mathrm{m}$ NC,

559 GE Healthcare Life sciences, 10600003).

560

\section{Cell Synchronization and Cell Cycle Analysis of MAP Kinase Activity}

562 Cell synchronization experiments were performed as described (Breeden, 1997). The

563 strain harboring Clb2p-HA (PC2744) was transformed with a plasmid containing the

564 STE4 gene [pSTE4 (Stevenson et al., 1992)]. Cells were grown to an optical density

565 (O.D.) $\mathrm{A}_{600}$ of 0.2 in SD-URA media. Cells were washed and resuspended in equal

566 volume of YEPD and incubated for $90 \mathrm{~min}$ at $30^{\circ} \mathrm{C}$. $\alpha$-factor was added to a final

567 concentration of $5 \mu \mathrm{g} / \mathrm{ml}$ and the culture was incubated for $90 \mathrm{~min}$ to arrest cells in the $\mathrm{G}_{1}$

568 phase of the cell cycle. Arrested cells were washed twice with water and resuspended in

569 fresh YEPD or YEP-GAL media to release cells into the cell cycle. $10 \mathrm{ml}$ aliquots were

570 harvested every $10 \mathrm{~min}$, flash frozen in liquid nitrogen and stored at $-80^{\circ} \mathrm{C}$.

571

572 Immunoblot Analysis

573 ERK-type MAP kinases ( $P \sim \mathrm{Kss} 1 \mathrm{p}$ and $\mathrm{P} \sim \mathrm{Fus} 3 \mathrm{p})$ were detected using p44/42 antibodies

574 (Cell Signaling Technology, Danvers, MA, 4370) at a 1:5,000 dilution. Kss1p was

575 detected using $\alpha-$ Kss1p antibodies (Santa Cruz Biotechnology, Santa Cruz, CA; \#6775)

576 at a 1:5,000 dilution. Clb2p-HA was detected using the $\alpha$-HA antibody at a 1:5,000

577 dilution (Roche Diagnostics, 12CA5). For secondary antibodies, goat anti-rabbit IgG-

578 HRP antibodies were used at a 1:10,000 dilution (Jackson ImmunoResearch Laboratories, 
579 Inc., West Grove, PA, 111-035-144). Mouse $\alpha$-Pgk1p antibodies were used at a 1:5,000

580 dilution as a control for total protein levels (Novex, 459250). Goat $\alpha$-mouse secondary

581 antibodies were used at a 1:5,000 dilution to detect primary antibodies (Bio-Rad

582 Laboratories, Hercules, CA, 170-6516). Blots were visualized by chemiluminescence

583 using a Bio-Rad ChemiDoc XRS+ system (Bio-Rad, 1708265). Quantitation of band

584 intensities for immunoblot analysis was performed with Image Lab Software (Bio-Rad,

585 Inc.). For blots to evaluate phosphorylated MAP kinase proteins, membranes were

586 incubated in 1X TBST (10 mM TRIS-HCl pH 8, $150 \mathrm{mM} \mathrm{NaCl}, 0.05 \%$ Tween 20) with

$5875 \%$ BSA. For other immunoblots, membranes were incubated in $1 \mathrm{X}$ TBST with 5\% non-

588 fat dried milk. All primary incubations were carried out at $16 \mathrm{~h}$ at $4^{\circ} \mathrm{C}$. Secondary

589 incubations were carried out at $25^{\circ} \mathrm{C}$ for $1 \mathrm{~h}$.

591 Growth Assays for Temperature-Sensitive Mutants

592 Wild type and temperature-sensitive mutants containing desired plasmids were grown to

593 saturation in SD-URA media. For each strain, O.1 O.D.600 of cells were serially diluted 4

594 times in distilled water and spotted onto SD-URA-LEU+ 0.5M Sorbitol plates. The plates

595 were incubated at $30^{\circ} \mathrm{C}$ and $37^{\circ} \mathrm{C}$. For $c d c 12-6$ suppression, cells were spotted onto SD-

596 URA plates and incubated at $24^{\circ} \mathrm{C}$ and $30^{\circ} \mathrm{C}$ since the $c d c 12-6$ mutant had a severe

597 growth defect at $30^{\circ} \mathrm{C}$ and failed to grow completely at $37^{\circ} \mathrm{C}$. For all suppression assays,

598 plates were photographed every day for 4 days using Evolution MP Color Camera

599 (Media Cybernetics) and Q Capture software. Images were imported into ImageJ

600 software. Cells of interest were selected and measure tool was used to generate values for

601 the integrated density, area and the mean signal intensity. Growth of a colony was 
602 quantified by measuring the signal intensity of the colony against the background using

603 the formula, corrected signal intensity = Integrated Density $-($ Area of selected cell X

604 Mean signal intensity of the background cell). Growth at $37^{\circ} \mathrm{C}$ was compared to growth

605 at $30^{\circ} \mathrm{C}$ for each strain and then normalized to wild type. Quantitation was reported for

606 the day where the temperature-sensitive mutant containing STE11-4 plasmid showed

607 around $60 \%$ of growth compared to the wild type, which was the maximum growth

608 detected across various mutant combinations and independent trials. For most analysis,

609 only the first or the second dilution of cells was used for the quantitation. All growth

610 assays were performed in triplicate. Error bars show standard error of mean among the 3

611 trials.

612

613 Quantitative PCR Analysis

614 Cells for $\mathrm{qPCR}$ were concentrated $\left(\mathrm{OD} \mathrm{A}_{600}=20\right)$ and spotted in $10 \mu \mathrm{l}$ aliquots onto

615 YEP-GAL (2\% agar) for $24 \mathrm{~h}$. Cells were spotted in six colonies per plate equidistant to

616 each other and the plate center. All six colonies were harvested for each trial, and two

617 separate trials were compared for each strain. The entire colony surface was scraped into

$618500 \mu \mathrm{l}$ of distilled water, harvested by centrifugation, washed, and stored at $-80^{\circ} \mathrm{C}$. RNA

619 was harvested by hot acid phenol chloroform extraction as described (Adhikari and

620 Cullen, 2014). Samples were further purified using Qiagen RNeasy Mini Kit (Cat.

621 74104). RNA concentration and purity was measured using NanoDrop (NanoDrop

622 2000C). RNA stability was determined by 1\% agarose Tris-Borate-EDTA (TBE, $89 \mathrm{mM}$

623 Tris base, $89 \mathrm{mM}$ Boric acid, 2 mM EDTA) gel electrophoresis. 
625 Transcriptase Supermix (BioRad, 1708840). qPCR was performed using iTaq Universal

626 SYBR Green Supermix (BioRad, 1725120) on BioRad (CFX384 Real-Time System).

627 Fold changes in expression were determined by calculating $\triangle \Delta \mathrm{Ct}$ using $A C T 1 \mathrm{mRNA}$ as

628 the housekeeping gene for each sample. Experiments were performed with biological

629 replicates, and the average of multiple independent experiments were recorded. Primers

630 for pPCR for GIC2 were forward 5'- GCGCCAACAAGACAAATCACAAA-3' and

631 reverse 5'- GCAATTGCTCATCTTGGAATCC-3'. Primers for GIC1 were forward 5'-

632 GCCGAACAAGAACAACATCAA-3' and reverse 5'-

633 GTtTTGGCAGACCCATGTCTC-3'. Primers for ACT1 were forward 5'-

634 GGCTTCTTTGACTACCTTCCAACA-3' and reverse 5'-

635 GATGGACCACTTTCGTCGTATTC-3' as published (Chavel et al., 2010).

636

637 DIC and Fluorescence Microscopy

638 Differential-interference-contrast (DIC) and fluorescence microscopy using FITC, CFP, 639 YFP, Rhodamine, and DAPI filter sets were performed using an Axioplan 2 fluorescent 640 microscope (Zeiss) with a Plan-Apochromat 100X/1.4 (oil) objective (N.A. 1.4) (cover 641 slip 0.17) (Zeiss). Digital images were obtained with the Axiocam MRm camera (Zeiss) 642 and Axiovision 4.4 software (Zeiss). Adjustments to brightness and contrast were made 643 in Adobe Photoshop. Some images were obtained using structural deconvolution with a 644 Zeiss Apotome filter. Multiple polarization events were assigned by examining cells over 645 multiple focal planes by DIC and fluorescence microscopy. Time-lapse microscopy was 646 performed on a Zeiss 710 confocal microscope equipped with a Plan-Apochromat 
MAPK Pathway Regulates Bud Emergence_ Prabhakar et al.

$64740 x / 1.4$ Oil DIC M27 objective on a heated stage at $37^{\circ} \mathrm{C}$. GFP was imaged using $488 \mathrm{~nm}$

648 laser excitation and emission window from 496nm-572nm. Time-lapse $Z$ stacks were

649 captured at $10 \mathrm{~min}$ and $20 \mathrm{~min}$ intervals to monitor bud emergence and Cdc42p

650 clustering.

651

\section{Budding Rate Assay}

653 Cells were grown for $16 \mathrm{~h}$ on $\mathrm{SD}+\mathrm{AA}$ medium. Using a toothpick, cells were removed

654 from the plate, washed twice with water and resuspended in $1 \mathrm{ml}$ water. $50 \mu \mathrm{l}$ of cells

655 were spread onto SD+AA or S-GAL+AA media and incubated at $30^{\circ} \mathrm{C}$. Cells were

656 visualized at $0,5,10$ and $18 \mathrm{~h}$ intervals at $20 \mathrm{X}$. Budding rate, $\ln (\mathrm{n}) / \ln (2)$, was

657 determined as described (Hall et al., 2014), where $\mathrm{n}$ is the number of daughters produced.

658 Budding rate was adjusted for the time interval $(5 \mathrm{~h}, 5 \mathrm{~h}$ and $8 \mathrm{~h})$. More than 30 cells

659 were examined for each interval.

660

661 Time Lapse Microscopy

662 For time lapse microscopy, cells were placed onto semi-solid agarose pads that were

663 prepared as described (Skinner et al., 2013) with the following modifications.

664 Approximately $700 \mu \mathrm{l}$ of SD-URA media, prepared with agarose (1\%), was placed inside

$66512 \mathrm{~mm}$ Nunc glass base dishes (150680, Thermo Scientific, Waltham, MA) and allowed 666 to set at $25^{\circ} \mathrm{C}$ for $5 \mathrm{~min}$.

667 For GFP-Cdc42p clustering in $c d c 24-4$ mutant combinations, cells were taken

668 from colonies grown at $30^{\circ} \mathrm{C}$ for $16 \mathrm{~h}$ on SD-URA+G418 semi-sold agar media [2\%

669 agarose, $0.67 \%$ YNB without ammonium sulfate, $0.1 \%$ monosodium glutamate (MSG), 
$6702 \%$ dextrose, $1 \mathrm{X}$ amino acid stock without uracil, $0.36 \mathrm{mg} / \mathrm{ml} \mathrm{G} 418]$, resuspended in 7

$671 \mu \mathrm{l}$ of synthetic broth ( $0.67 \%$ YNB without ammonium sulfate, $0.1 \%$ MSG, $2 \%$ dextrose),

672 and placed under the agarose pads by gently lifting the pad with a scalpel. $100 \mu$ of water

673 was placed in the dish adjacent to the agarose pad to prevent moisture loss, and the petri

674 dishes were incubated at $37^{\circ} \mathrm{C}$ for $4 \mathrm{~h}$. For co-localization of Sholp-GFP and Gic2p-

675 PBD-tdTomato, cells were prepared as above except imaged at $30^{\circ} \mathrm{C}$. For GFP-Cdc42p

676 clustering in cells carrying $M S B 2^{\Delta 100-818}, 500 \mu 1$ of saturated culture was washed twice

677 with water and resuspended in $500 \mu \mathrm{l}$ water. $5 \mu \mathrm{l}$ was placed under the agarose pad, and

678 the petri dish was incubated at $30^{\circ} \mathrm{C}$ for $10 \mathrm{~h}$ before imaging. For strains expressing GFP-

$679 \mathrm{Cdc} 42 \mathrm{p}$ and $\mathrm{Cdc} 3 \mathrm{p}-\mathrm{mCherry}$, cells were prepared from colonies grown at $30^{\circ} \mathrm{C}$ for $16 \mathrm{~h}$ 680 on SD-URA.

\section{$682 \quad$ FLIM-FRET Analysis}

683 Plasmids containing the Cdc42p biosensor have been described (Smith et al., 2013) and 684 were a generous gift from Dr. Rong Li (Johns Hopkins University, Baltimore MD). Cells 685 containing pRS316-pACT1-eGFP-CRIBCLA4-Cdc42 ${ }^{\mathrm{C}}{ }^{\mathrm{CAAX}}-$ mCherry-CAAX (PC7137), 686 and Q61L (PC7138) or D57Y (PC7139) derivatives, were grown on SD-URA medium to 687 maintain selection for the plasmids. Semi-solid agarose pads were prepared as described 688 above. Cells were taken from colonies grown for $16 \mathrm{~h}$ on semi-solid agar medium (SD689 URA), resuspended in $7 \mu$ of SD broth, and placed under the agarose pads.

691 Confocal Imaging Facility. FLIM-FRET has been described (Gratton et al., 2003;

692 Periasamy and Clegg, 2009; Osterlund et al., 2015; Padilla-Parra et al., 2015; Sun and 
MAPK Pathway Regulates Bud Emergence

Prabhakar et al.

693 Periasamy, 2015; Bassard and Halkier, 2018). FLIM-FRET images were acquired with a

694 Simple Tau TCSPC 150 and HPM-100-40 GaAsP detector (Becker \& Hickl GmbH)

695 employing the direct coupled port of the LSM 710 and Zeiss Intune Laser excitation at

$696490 \mathrm{~nm}$. At least 1000 photons per pixel were acquired for the highest count region for

697 each cell.

698 FLIM-FRET data analysis was performed using SPCImage 7.3 (Becker \& Hickl

$699 \mathrm{GmbH})$. Data was fit by a two-component exponential decay model and automatically

700 generated Instrument Response Function (IRF). Bin factor, shift and offset were adjusted

701 to obtain good fit (low $\chi^{2}$ ). For measuring the average lifetime, the decay curve was

702 pooled for the region of interest. The mean fluorescence lifetime for two-component

703 decay model was calculated according to the equation:

$$
\tau_{m}=a_{1} \tau_{1}+a_{2} \tau_{2}
$$

704 where $a_{i}$ and $\tau_{i}$ are the amplitude and lifetime of the ith component. $\tau_{m}$ is the average

705 lifetime of the donor fluorescence. More than 20 cells were counted for each strain.

707 Scanning Electron Microscopy

708 Scanning electron microscopy (SEM) was based on established methods (Piccirillo and

709 Honigberg, 2011) and performed essentially as described (Basu et al., 2016). For some

710 experiments, cells were grown for $16 \mathrm{~h}$ in liquid media at $30^{\circ} \mathrm{C}$. Cells were washed in 0.1

711 M sodium phosphate buffer $\mathrm{pH} 7.4$ and diluted to about $10^{6}$ cells, which were passed

712 over 0.2 micron Whatman nucleopore polycarbonate filter paper with a $10 \mathrm{~mL}$ syringe

713 (GE Whatman, catalog \#889-78084; BD Syringe, \#309604). Cells were rinsed with one

714 round of buffer by syringe, fixed with $1 \%$ glutaraldehyde for 15 minutes, and rinsed 
715 again. Cells were treated by a graded series of ethanol washes $(30 \%, 50 \%, 70 \%, 85 \%$,

716 and $100 \%$ ) by syringe to dehydrate the samples. The filter paper was removed from the

717 holder, placed in a petri dish and treated with hydroxymethyldiazane (HMDS). Samples

718 were placed at $4^{\circ} \mathrm{C}$ for $16 \mathrm{~h}$ and imaged the following day. All solutions were filter

719 sterilized before use and stored in clean containers free of corrosion products. Samples

720 were carbon coated and imaged on a FE-SEM (Field emission scanning electron

721 microscope) Hitachi SU70.

\section{$723 \quad$ Image Analysis}

724 Gic2p-PBD-tdTomato clustering was quantified as described in (Okada et al., 2017) with

725 following modifications. Raw fluorescence and DIC images were imported in ImageJ.

726 DIC image was used to draw the cell boundary with the polygon tool. The same region of

727 interest (ROI) was applied to the fluorescence image. Signal intensities for all pixels

728 inside the ROI were exported as a CSV file using save XY coordinates option under

729 Analyze- tool menu. A custom MATLAB (MATLAB R2016b, The MathWorks, Inc.,

730 Natick, MA) code (available on request) was designed to analyze the CSV files. In the

731 analysis, mean and standard deviation (STD) of all the pixels of a cell were calculated.

732 The pixel intensity that was greater than the mean+2 STD was selected. A region of the

733 image where no cell was present was chosen as the background and the average pixel

734 intensity of the background region was subtracted from the selected pixels of the cell.

735 The signal intensity for each of these background subtracted pixels was normalized to the

736 peak value which was set to 1 . The sum of these normalized pixels was used to represent

737 each cell. Over 60 cells were measured for each sample. 
MAPK Pathway Regulates Bud Emergence

Prabhakar et al.

Time lapse microscopy images were processed in ImageJ. Grayscale fluorescence

739 images were converted into maximum intensity projection and inverted. Quantitation of

740 timing of Cdc42p clustering was performed as described (McClure et al., 2016; Lai et al.,

741 2018) with following modifications. Threshold was applied to the 16-bit grayscale image

742 to highlight cells and converted to binary image. Any merged cells were separated using

743 watershed plugin after applying Gaussian Blur filter with sigma value of 2. Using

744 Analyze Particles tab, the binary image was used to analyze the grayscale image to

745 calculate mean intensity and standard deviation of each cell. Coefficient of Variance was

746 then calculated from the mean and standard deviation and plotted as a function of time.

747 Kymographs were made on inverted maximum intensity projection image.

748 Brightness and contrast was adjusted uniformly for each time frame and each strain. Line

749 tool with pixel width of 1 was used to define region of interest and Reslice tool was used

750 to generate slices for each time frame.

751

752 Bioinformatics and Statistical Analysis

753 GO term analysis (Ashburner et al., 2000) was performed using the Gene Ontology

754 enRIchment analysis and visuaLizAtion algorithm (GOrilla) (Eden et al., 2007; Eden et

755 al., 2009) using the two unranked lists mode. Genes encoding proteins associated with

756 cell polarity were identified by GO term analysis [(Ashburner et al., 2000), GO:0000282,

757 cellular bud site selection; GO:0030010, establishment of cell polarity; GO:0031106,

758 septin ring organization; GO:0006887, exocytosis; GO:0007120, axial cellular bud site

759 selection; GO0007121, bipolar cellular bud site selection; GO:0030427, site of polarized

760 growth]. GO terms and descriptions come from SGD (http://www.yeastgenome.org). 
MAPK Pathway Regulates Bud Emergence

Prabhakar et al.

761 Statistical significance for pair-wise comparisons was performed using Student's t-Test in

762 Microsoft Excel. For multiple comparisons, one-way ANOVA with Tukey test was

763 performed in Minitab (www.minitab.com).

764

765 ABBREVIATIONS

766 3-ATA, 3-Amino-1,2,4-triazole; 5-FOA, 5-fluoroorotic acid; CFP, cyan fluorescent

767 protein; D, dextrose; GAL, galactose; GAP, GTPase activating protein; GEF, guanine

768 nucleotide exchange factor; GTPase, guanine nucleotide triphosphatase; GFP, green

769 fluorescent protein; GLU, glucose; HA, hemaglutinin; HOG, high osmolarity glycerol

770 response; Lat-A, Latrunculin-A; MAPK, mitogen activated protein kinase; MSG,

771 Monosodium Glutamate; PAK, p21 activated kinase; qPCR, quantitative polymerase

772 chain reaction; PM, plasma membrane; Rho, Ras homology; SDS-PAGE, sodium

773 dodecyl sulfate-polyacrylamide gel electrophoresis; TBE, Tris-Borate-EDTA; TCA,

774 trichloroacetic acid; WT, wild type; and YFP, yellow fluorescent protein; and YNB,

775 Yeast Nitrogen base.

776

777 ACKNOWLEDGEMENTS

778 Thanks to Matthias Peter (ETH Zürich), D. Lew (Duke University), John Pringle

779 (Stanford University), Rong Li (Johns Hopkins University, Baltimore MD), Charlie

780 Boone (University of Toronto), Alan Davidson (University of Toronto), Scott Emr

781 (Cornell University), Peter Novick (Yale University), Erfei Bi (UPENN) and Mike Yu

782 (SUNY-Buffalo) for providing strains and/or plasmids. Thanks to Steve Free (SUNY-

783 Buffalo) for comments. Karnesh Jain (University of North Dakota) wrote the MATLAB 
MAPK Pathway Regulates Bud Emergence

Prabhakar et al.

784

785

786

787

788

789

790

791

792

793

794

795

796

797

798

799

800

801

802

803

804

805

806

807

808

809

810

811

812

813

814

815

816

817

818

819

820

code for quantifying Gic2p-PBD-tdTomato signal. Nadia Vadiae, Pu Zheng, Minakshi

Mukherjee, Matt Vandermeulen and Shally Lin helped with experiments. Attendance at

the $18^{\text {th }}$ annual workshop on FLIM and FRET microscopy at W.M. Keck Center for

Cellular Imaging at the University of Virginia (hosted by Ammasi Periasamy), came

from a travel award from the Histochemical Society (for A.P.). The work was supported

from a grant from the NIH (GM\#098629).

\section{REFERENCES}

Adhikari, H., and Cullen, P.J. (2014). Metabolic Respiration Induces AMPK- and Ire1pDependent Activation of the p38-Type HOG MAPK Pathway. PLoS genetics 10, e1004734.

Adhikari, H., Vadaie, N., Chow, J., Caccamise, L.M., Chavel, C.A., Li, B., Bowitch, A., Stefan, C.J., and Cullen, P.J. (2015). Role of the unfolded protein response in regulating the mucin-dependent filamentous-growth mitogen-activated protein kinase pathway. Molecular and cellular biology 35, 1414-1432.

Arkowitz, R.A., and Iglesias, P.A. (2008). Basic principles of polarity establishment and maintenance. Conference on Mechanisms of Cell Polarity. EMBO reports 9, 847-852.

Ashburner, M., Ball, C.A., Blake, J.A., Botstein, D., Butler, H., Cherry, J.M., Davis, A.P., Dolinski, K., Dwight, S.S., Eppig, J.T., Harris, M.A., Hill, D.P., Issel-Tarver, L., Kasarskis, A., Lewis, S., Matese, J.C., Richardson, J.E., Ringwald, M., Rubin, G.M., and Sherlock, G. (2000). Gene ontology: tool for the unification of biology. The Gene Ontology Consortium. Nat Genet 25, 25-29.

Bardwell, L., Cook, J.G., Zhu-Shimoni, J.X., Voora, D., and Thorner, J. (1998). Differential regulation of transcription: repression by unactivated mitogen-activated protein kinase Kss1 requires the Dig1 and Dig2 proteins. Proceedings of the National Academy of Sciences of the United States of America 95, 15400-15405.

Bassard, J.E., and Halkier, B.A. (2018). How to prove the existence of metabolons? Phytochemistry reviews : proceedings of the Phytochemical Society of Europe 17, 211227.

Basu, S., Gonzalez, B., Li, B., Kimble, G., Kozminski, K., and Cullen, P.J. (UNDER REVIEW). Functions for Cdc42p Adaptors in Regulating a Differentiation-Type MAP Kinase Pathway.

Basu, S., Vadaie, N., Prabhakar, A., Li, B., Adhikari, H., Pitoniak, A., Chow, J., Chavel, C.A., and Cullen, P.J. (2016). Spatial landmarks regulate a Cdc42-dependent MAPK pathway to control differentiation and the response to positional compromise. Proceedings of the National Academy of Sciences of the United States of America 113, E2019-2028. 
821 Baudin, A., Ozier-Kalogeropoulos, O., Denouel, A., Lacroute, F., and Cullin, C. (1993). 822 A simple and efficient method for direct gene deletion in Saccharomyces cerevisiae. 823 Nucleic Acids Res 21, 3329-3330.

824 Bauer, Y., Knechtle, P., Wendland, J., Helfer, H., and Philippsen, P. (2004). A Ras-like 825 GTPase is involved in hyphal growth guidance in the filamentous fungus Ashbya 826 gossypii. Molecular biology of the cell 15, 4622-4632.

827 Bender, A., and Pringle, J.R. (1989). Multicopy suppression of the cdc24 budding defect 828 in yeast by CDC42 and three newly identified genes including the ras-related gene RSR1. 829 Proceedings of the National Academy of Sciences of the United States of America 86, $8309976-9980$.

831 Bender, A., and Pringle, J.R. (1992). A Ser/Thr-rich multicopy suppressor of a cdc24 bud 832 emergence defect. Yeast 8, 315-323.

833 Bendezu, F.O., and Martin, S.G. (2013). Cdc42 explores the cell periphery for mate 834 selection in fission yeast. Current biology : CB 23, 42-47.

Bi, E., and Park, H.O. (2012). Cell polarization and cytokinesis in budding yeast. Genetics 191, 347-387.

840 Borneman, A.R., Gianoulis, T.A., Zhang, Z.D., Yu, H., Rozowsky, J., Seringhaus, M.R., Wang, L.Y., Gerstein, M., and Snyder, M. (2007). Divergence of transcription factor binding sites across related yeast species. Science 317, 815-819.

844 Breeden, L.L. (1997). $\alpha$-Factor synchronization of budding yeast. In: Methods in Enzymology, vol. 283: Academic Press, 332-342. Brewster, J.L., de Valoir, T., Dwyer, N.D., Winter, E., and Gustin, M.C. (1993). An osmosensing signal transduction pathway in yeast. Science 259, 1760-1763.

Brown, J.L., Jaquenoud, M., Gulli, M.P., Chant, J., and Peter, M. (1997). Novel Cdc42binding proteins Gic1 and Gic2 control cell polarity in yeast. Genes \& development 11, 2972-2982. Ste20 homologue hPAK1 links GTPases to the JNK MAP kinase pathway. Current biology : CB 6, 598-605. GTPase-activating proteins in assembly of the septin ring in yeast. Molecular biology of the cell 14, 4051-4066.

Caviston, J.P., Tcheperegine, S.E., and Bi, E. (2002). Singularity in budding: a role for the evolutionarily conserved small GTPase Cdc42p. Proceedings of the National Academy of Sciences of the United States of America 99, 12185-12190.

856 Cepeda-Garcia, C. (2017). Determination of Cell Cycle Stage and Mitotic Exit Through the Quantification of the Protein Levels of Known Mitotic Regulators. Methods in molecular biology (Clifton, N.J.) 1505, 45-57.

861 Chen, G.-C., Kim, Y.-J., and Chan, C.S.M. (1997). The Cdc42 GTPase-associated proteins Gic1 and Gic2 are required for polarized cell growth in

864 Chen, H., Kuo, C.C., Kang, H., Howell, A.S., Zyla, T.R., Jin, M., and Lew, D.J. (2012). 865 Cdc42p regulation of the yeast formin Bnilp mediated by the effector Gic2p. Molecular 866 biology of the cell 23, 3814-3826. 
Chiou, J.G., Balasubramanian, M.K., and Lew, D.J. (2017). Cell Polarity in Yeast. Annual review of cell and developmental biology 33, 77-101.

Chiou, J.G., Ramirez, S.A., Elston, T.C., Witelski, T.P., Schaeffer, D.G., and Lew, D.J. (2018). Principles that govern competition or co-existence in Rho-GTPase driven polarization. PLoS computational biology 14, e1006095.

Cho, R.J., Campbell, M.J., Winzeler, E.A., Steinmetz, L., Conway, A., Wodicka, L., Wolfsberg, T.G., Gabrielian, A.E., Landsman, D., Lockhart, D.J., and Davis, R.W. (1998). A genome-wide transcriptional analysis of the mitotic cell cycle. Mol Cell 2, 6573.

Chow, J., Starr, I., Jamalzadeh, S., Muniz, O., Kumar, A., Gokcumen, O., Ferkey, D.M., and Cullen, P.J. (2019). Filamentation Regulatory Pathways Control AdhesionDependent Surface Responses in Yeast. Genetics.

Cid, V.J., Adamikova, L., Sanchez, M., Molina, M., and Nombela, C. (2001). Cell cycle control of septin ring dynamics in the budding yeast. Microbiology (Reading, England) 147, 1437-1450.

Costanzo, M., Baryshnikova, A., Bellay, J., Kim, Y., Spear, E.D., Sevier, C.S., Ding, H., Koh, J.L., Toufighi, K., Mostafavi, S., Prinz, J., St Onge, R.P., VanderSluis, B., Makhnevych, T., Vizeacoumar, F.J., Alizadeh, S., Bahr, S., Brost, R.L., Chen, Y., Cokol, M., Deshpande, R., Li, Z., Lin, Z.Y., Liang, W., Marback, M., Paw, J., San Luis, B.J., Shuteriqi, E., Tong, A.H., van Dyk, N., Wallace, I.M., Whitney, J.A., Weirauch, M.T., Zhong, G., Zhu, H., Houry, W.A., Brudno, M., Ragibizadeh, S., Papp, B., Pal, C., Roth, F.P., Giaever, G., Nislow, C., Troyanskaya, O.G., Bussey, H., Bader, G.D., Gingras, A.C., Morris, Q.D., Kim, P.M., Kaiser, C.A., Myers, C.L., Andrews, B.J., and Boone, C. (2010). The genetic landscape of a cell. Science 327, 425-431.

Cross, F.R., Schroeder, L., Kruse, M., and Chen, K.C. (2005). Quantitative characterization of a mitotic cyclin threshold regulating exit from mitosis. Molecular biology of the cell 16, 2129-2138.

Cullen, P.J. (2015). Evaluating yeast filamentous growth at the single-cell level. Cold Spring Harbor protocols 2015, 272-275.

Cullen, P.J., Sabbagh, W., Jr., Graham, E., Irick, M.M., van Olden, E.K., Neal, C., Delrow, J., Bardwell, L., and Sprague, G.F., Jr. (2004). A signaling mucin at the head of the Cdc42- and MAPK-dependent filamentous growth pathway in yeast. Genes \& development 18, 1695-1708.

Cullen, P.J., and Sprague, G.F., Jr. (2000). Glucose depletion causes haploid invasive growth in yeast. Proceedings of the National Academy of Sciences of the United States of America 97, 13619-13624.

Cullen, P.J., and Sprague, G.F., Jr. (2002). The roles of bud-site-selection proteins during haploid invasive growth in yeast. Molecular biology of the cell 13, 2990-3004.

Cvrckova, F., De Virgilio, C., Manser, E., Pringle, J.R., and Nasmyth, K. (1995). Ste20like protein kinases are required for normal localization of cell growth and for cytokinesis in budding yeast. Genes \& development 9, 1817-1830.

Daniels, C.N., Zyla, T.R., and Lew, D.J. (2018). A role for Gic1 and Gic2 in Cdc42 polarization at elevated temperature. PloS one 13, e0200863.

Das, M., Drake, T., Wiley, D.J., Buchwald, P., Vavylonis, D., and Verde, F. (2012). Oscillatory dynamics of Cdc42 GTPase in the control of polarized growth. Science 337, 239-243. 
913 Das, M., Wiley, D.J., Medina, S., Vincent, H.A., Larrea, M., Oriolo, A., and Verde, F. 914 (2007). Regulation of cell diameter, For3p localization, and cell symmetry by fission 915 yeast Rho-GAP Rga4p. Mol Biol Cell 18, 2090-2101.

916 Davenport, K.D., Williams, K.E., Ullmann, B.D., and Gustin, M.C. (1999). Activation of 917 the Saccharomyces cerevisiae filamentation/invasion pathway by osmotic stress in high918 osmolarity glycogen pathway mutants. Genetics 153, 1091-1103.

919 Desai, J.V., Mitchell, A.P., and Andes, D.R. (2014). Fungal biofilms, drug resistance, and 920 recurrent infection. Cold Spring Harb Perspect Med 4.

921 Dinsmore, C.J., and Soriano, P. (2018). MAPK and PI3K signaling: At the crossroads of neural crest development. Developmental biology 444 Suppl 1, S79-s97.

924 Opin Genet Dev 57, 47-53.

925 Dyer, J.M., Savage, N.S., Jin, M., Zyla, T.R., Elston, T.C., and Lew, D.J. (2013). Tracking shallow chemical gradients by actin-driven wandering of the polarization site. Current biology : CB 23, 32-41.

930

931

932

Eden, E., Lipson, D., Yogev, S., and Yakhini, Z. (2007). Discovering motifs in ranked lists of DNA sequences. PLoS Comput Biol 3, e39.

933 Eluere, R., Offner, N., Varlet, I., Motteux, O., Signon, L., Picard, A., Bailly, E., and 934 Simon, M.N. (2007). Compartmentalization of the functions and regulation of the mitotic Eden, E., Navon, R., Steinfeld, I., Lipson, D., and Yakhini, Z. (2009). GOrilla: a tool for discovery and visualization of enriched $\mathrm{GO}$ terms in ranked gene lists. BMC Bioinformatics 10, 48. cyclin Clb2 in S. cerevisiae. J Cell Sci 120, 702-711.

Evangelista, M., Blundell, K., Longtine, M.S., Chow, C.J., Adames, N., Pringle, J.R., Peter, M., and Boone, C. (1997). Bnilp, a yeast formin linking cdc42p and the actin cytoskeleton during polarized morphogenesis. Science 276, 118-122.

939

940

941

942 Fares, H., Goetsch, L., and Pringle, J.R. (1996). Identification of a developmentally regulated septin and involvement of the septins in spore formation in Saccharomyces cerevisiae. The Journal of cell biology 132, 399-411.

Finger, F.P., and Novick, P. (1997). Sec3p is involved in secretion and morphogenesis in Saccharomyces cerevisiae. Molecular biology of the cell 8, 647-662.

948 Freisinger, T., Klünder, B., Johnson, J., Müller, N., Pichler, G., Beck, G., Costanzo, M.,

952 Gancedo, J.M. (2001). Control of pseudohyphae formation in Saccharomyces cerevisiae. 953 FEMS Microbiol Rev 25, 107-123.

954 Gandhi, M., Goode, B.L., and Chan, C.S. (2006). Four novel suppressors of gic1 gic2 and 955 their roles in cytokinesis and polarized cell growth in Saccharomyces cerevisiae. Genetics 956 174, 665-678.

957 Gelperin, D.M., White, M.A., Wilkinson, M.L., Kon, Y., Kung, L.A., Wise, K.J., Lopez958 Hoyo, N., Jiang, L., Piccirillo, S., Yu, H., Gerstein, M., Dumont, M.E., Phizicky, E.M., 
959

960

961

962

963

964

965

966

967

968

969

970

971

972

973

974

975

976

977

978

979

980

981

982

983

984

985

986

987

988

989

990

991

992

993

994

995

996

997

998

999

1000

1001

1002

1003

Snyder, M., and Grayhack, E.J. (2005). Biochemical and genetic analysis of the yeast proteome with a movable ORF collection. Genes \& development 19, 2816-2826.

Gimeno, C.J., and Fink, G.R. (1994). Induction of pseudohyphal growth by overexpression of PHD1, a Saccharomyces cerevisiae gene related to transcriptional regulators of fungal development. Molecular and cellular biology 14, 2100-2112.

Gimeno, C.J., Ljungdahl, P.O., Styles, C.A., and Fink, G.R. (1992). Unipolar cell divisions in the yeast $\mathrm{S}$. cerevisiae lead to filamentous growth: regulation by starvation and RAS. Cell 68, 1077-1090.

Gladfelter, A.S., Bose, I., Zyla, T.R., Bardes, E.S.G., and Lew, D.J. (2002). Septin ring assembly involves cycles of GTP loading and hydrolysis by Cdc42p. The Journal of Cell Biology 156, 315.

Gladfelter, A.S., Kozubowski, L., Zyla, T.R., and Lew, D.J. (2005). Interplay between septin organization, cell cycle and cell shape in yeast. Journal of Cell Science 118, 1617.

Gladfelter, A.S., Moskow, J.J., Zyla, T.R., and Lew, D.J. (2001). Isolation and characterization of effector-loop mutants of CDC42 in yeast. Molecular biology of the cell 12, 1239-1255.

Goldstein, A.L., and McCusker, J.H. (1999). Three new dominant drug resistance cassettes for gene disruption in Saccharomyces cerevisiae. Yeast 15, 1541-1553.

Gratton, E., Breusegem, S., Sutin, J., Ruan, Q., and Barry, N. (2003). Fluorescence lifetime imaging for the two-photon microscope: time-domain and frequency-domain methods. Journal of biomedical optics 8, 381-390.

Gulli, M.P., Jaquenoud, M., Shimada, Y., Niederhauser, G., Wiget, P., and Peter, M. (2000). Phosphorylation of the Cdc42 exchange factor Cdc24 by the PAK-like kinase Cla4 may regulate polarized growth in yeast. Molecular cell 6, 1155-1167.

Guo, F., Hildeman, D., Tripathi, P., Velu, C.S., Grimes, H.L., and Zheng, Y. (2010). Coordination of IL-7 receptor and T-cell receptor signaling by cell-division cycle 42 in T-cell homeostasis. Proceedings of the National Academy of Sciences of the United States of America 107, 18505-18510.

Hall, B.G., Acar, H., Nandipati, A., and Barlow, M. (2014). Growth rates made easy. Molecular biology and evolution 31, 232-238.

Harkins, H.A., Page, N., Schenkman, L.R., De Virgilio, C., Shaw, S., Bussey, H., and Pringle, J.R. (2001). Bud8p and Bud9p, proteins that may mark the sites for bipolar budding in yeast. Molecular biology of the cell 12, 2497-2518.

Hartwell, L.H., Culotti, J., and Reid, B. (1970). Genetic control of the cell-division cycle in yeast. I. Detection of mutants. Proceedings of the National Academy of Sciences of the United States of America 66, 352-359.

Henderson, D.J., Long, D.A., and Dean, C.H. (2018). Planar cell polarity in organ formation. Current opinion in cell biology 55, 96-103.

Hofmann, C., Shepelev, M., and Chernoff, J. (2004). The genetics of Pak. J Cell Sci 117, 4343-4354.

Howell, A.S., Jin, M., Wu, C.F., Zyla, T.R., Elston, T.C., and Lew, D.J. (2012). Negative feedback enhances robustness in the yeast polarity establishment circuit. Cell 149, 322333.

Howell, A.S., and Lew, D.J. (2012). Morphogenesis and the cell cycle. Genetics 190, 5177. 
1004

1005

1006

1007

1008

1009

1010

1011

1012

1013

1014

1015

1016

1017

1018

1019

1020

1021

1022

1023

1024

1025

1026

1027

1028

1029

1030

1031

1032

1033

1034

1035

1036

1037

1038

1039

1040

1041

1042

1043

1044

1045

1046

1047

1048

Howell, A.S., Savage, N.S., Johnson, S.A., Bose, I., Wagner, A.W., Zyla, T.R., Nijhout, H.F., Reed, M.C., Goryachev, A.B., and Lew, D.J. (2009). Singularity in polarization: rewiring yeast cells to make two buds. Cell 139, 731-743.

$\mathrm{Hu}$, Z., Killion, P.J., and Iyer, V.R. (2007). Genetic reconstruction of a functional transcriptional regulatory network. Nat Genet 39, 683-687.

Irazoqui, J.E., Gladfelter, A.S., and Lew, D.J. (2003). Scaffold-mediated symmetry breaking by Cdc42p. Nature cell biology 5, 1062-1070.

Irazoqui, J.E., and Lew, D.J. (2004). Polarity establishment in yeast. Journal of cell science $117,2169-2171$.

Irniger, S., Piatti, S., Michaelis, C., and Nasmyth, K. (1995). Genes involved in sister chromatid separation are needed for B-type cyclin proteolysis in budding yeast. Cell 81 , 269-278.

Iwase, M., Luo, J., Nagaraj, S., Longtine, M., Kim, H.B., Haarer, B.K., Caruso, C., Tong, Z., Pringle, J.R., and Bi, E. (2006). Role of a Cdc42p effector pathway in recruitment of the yeast septins to the presumptive bud site. Molecular biology of the cell 17, 11101125 .

Jaquenoud, M., Gulli, M.P., Peter, K., and Peter, M. (1998). The Cdc42p effector Gic2p is targeted for ubiquitin-dependent degradation by the SCF\&lt;sup\&gt;Grr1\&lt;/sup\&gt; complex. The EMBO Journal 17, 5360.

Jenness, D.D., Goldman, B.S., and Hartwell, L.H. (1987). Saccharomyces cerevisiae mutants unresponsive to alpha-factor pheromone: alpha-factor binding and extragenic suppression. Molecular and cellular biology 7, 1311-1319.

Jimeno, D., and Santos, E. (2017). A new functional role uncovered for RASGRF2 in control of nuclear migration in cone photoreceptors during postnatal retinal development. Small GTPases 8, 26-30.

Kadota, J., Yamamoto, T., Yoshiuchi, S., Bi, E., and Tanaka, K. (2004). Septin ring assembly requires concerted action of polarisome components, a PAK kinase Cla4p, and the actin cytoskeleton in Saccharomyces cerevisiae. Molecular biology of the cell 15, 5329-5345.

Kaksonen, M., Sun, Y., and Drubin, D.G. (2003). A pathway for association of receptors, adaptors, and actin during endocytic internalization. Cell 115, 475-487.

Kang, P.J., Miller, K.E., Guegueniat, J., Beven, L., and Park, H.O. (2018). The shared role of the Rsr1 GTPase and Gic1/Gic2 in Cdc42 polarization. Molecular biology of the cell 29, 2359-2369.

Kawasaki, R., Fujimura-Kamada, K., Toi, H., Kato, H., and Tanaka, K. (2003). The upstream regulator, Rsrlp, and downstream effectors, Giclp and Gic2p, of the Cdc42p small GTPase coordinately regulate initiation of budding in Saccharomyces cerevisiae. Genes to cells : devoted to molecular \& cellular mechanisms 8, 235-250.

Kim, H.B., Haarer, B.K., and Pringle, J.R. (1991). Cellular morphogenesis in the Saccharomyces cerevisiae cell cycle: localization of the CDC3 gene product and the timing of events at the budding site. J Cell Biol 112, 535-544.

Klimova, Z., Braborec, V., Maninova, M., Caslavsky, J., Weber, M.J., and Vomastek, T. (2016). Symmetry breaking in spreading RAT2 fibroblasts requires the MAPK/ERK pathway scaffold RACK1 that integrates FAK, p190A-RhoGAP and ERK2 signaling. Biochim Biophys Acta 1863, 2189-2200. 
Kozubowski, L., Saito, K., Johnson, J.M., Howell, A.S., Zyla, T.R., and Lew, D.J. (2008). Symmetry-breaking polarization driven by a Cdc42p GEF-PAK complex. Current biology : CB 18, 1719-1726.

Kron, S.J., Styles, C.A., and Fink, G.R. (1994). Symmetric cell division in pseudohyphae of the yeast Saccharomyces cerevisiae. Molecular biology of the cell 5, 1003-1022. mitotic functions of the yeast cyclin Clb2. Cell cycle (Georgetown, Tex.) 9, 2611-2619. Lagree, K., and Mitchell, A.P. (2017). Fungal Biofilms: Inside Out. Microbiol Spectr 5. Lai, H., Chiou, J.G., Zhurikhina, A., Zyla, T.R., Tsygankov, D., and Lew, D.J. (2018). Temporal regulation of morphogenetic events in Saccharomyces cerevisiae. Molecular biology of the cell 29, 2069-2083. Lamb, T.M., and Mitchell, A.P. (2003). The transcription factor Rim101p governs ion tolerance and cell differentiation by direct repression of the regulatory genes NRG1 and SMP1 in Saccharomyces cerevisiae. Molecular and cellular biology 23, 677-686.

Leberer, E., Wu, C., Leeuw, T., Fourest-Lieuvin, A., Segall, J.E., and Thomas, D.Y. (1997). Functional characterization of the Cdc42p binding domain of yeast Ste20p protein kinase. The EMBO journal 16, 83-97.

Lee, M.J., and Dohlman, H.G. (2008). Coactivation of G protein signaling by cell-surface receptors and an intracellular exchange factor. Current biology : CB 18, 211-215.

Leitao, R.M., and Kellogg, D.R. (2017). The duration of mitosis and daughter cell size are modulated by nutrients in budding yeast. The Journal of Cell Biology 216, 34633470 .

Lew, D.J., and Reed, S.I. (1993). Morphogenesis in the yeast cell cycle: regulation by Cdc28 and cyclins. J Cell Biol 120, 1305-1320.

Lippincott, J., Shannon, K.B., Shou, W., Deshaies, R.J., and Li, R. (2001). The Tem1 small GTPase controls actomyosin and septin dynamics during cytokinesis. J Cell Sci 114, 1379-1386.

Liu, H., Styles, C.A., and Fink, G.R. (1993). Elements of the yeast pheromone response pathway required for filamentous growth of diploids. Science 262, 1741-1744.

Liu, Y., Zhang, T., Sun, D., and Luo, G. (2019). The Cdc42 effectors Gic1 and Gic2 regulate polarized post-Golgi secretion. Cell \& bioscience 9, 33 .

Lo, H.J., Kohler, J.R., DiDomenico, B., Loebenberg, D., Cacciapuoti, A., and Fink, G.R. (1997). Nonfilamentous C. albicans mutants are avirulent. Cell 90, 939-949.

Loeb, J.D., Kerentseva, T.A., Pan, T., Sepulveda-Becerra, M., and Liu, H. (1999). Saccharomyces cerevisiae G1 cyclins are differentially involved in invasive and pseudohyphal growth independent of the filamentation mitogen-activated protein kinase pathway. Genetics 153, 1535-1546.

Longtine, M.S., McKenzie, A., 3rd, Demarini, D.J., Shah, N.G., Wach, A., Brachat, A., Philippsen, P., and Pringle, J.R. (1998). Additional modules for versatile and economical PCR-based gene deletion and modification in Saccharomyces cerevisiae. Yeast 14, 953961.

MacIsaac, K.D., Wang, T., Gordon, D.B., Gifford, D.K., Stormo, G.D., and Fraenkel, E. (2006). An improved map of conserved regulatory sites for Saccharomyces cerevisiae. BMC Bioinformatics 7, 113.

1094 Madhani, H.D., and Fink, G.R. (1997). Combinatorial control required for the specificity of yeast MAPK signaling. Science 275, 1314-1317. 
1095

1096

1097

1098

1099

1100

1101

1102

1103

1104

1105

1106

1107

1108

1109

1110

1111

1112

1113

1114

1115

1116

1117

1118

1119

1120

1121

1122

1123

1124

1125

1126

1127

1128

1129

1130

1131

1132

1133

1134

1135

1136

1137

1138

1139
Madhani, H.D., Galitski, T., Lander, E.S., and Fink, G.R. (1999). Effectors of a developmental mitogen-activated protein kinase cascade revealed by expression signatures of signaling mutants. Proceedings of the National Academy of Sciences of the United States of America 96, 12530-12535.

Madhani, H.D., Styles, C.A., and Fink, G.R. (1997). MAP kinases with distinct inhibitory functions impart signaling specificity during yeast differentiation. Cell 91, 673-684.

Marles, J.A., Dahesh, S., Haynes, J., Andrews, B.J., and Davidson, A.R. (2004). Proteinprotein interaction affinity plays a crucial role in controlling the Sholp-mediated signal transduction pathway in yeast. Molecular cell 14, 813-823.

Martin, S.G. (2019). Molecular mechanisms of chemotropism and cell fusion in unicellular fungi. Journal of cell science 132.

McCaffrey, G., Clay, F.J., Kelsay, K., and Sprague, G.F., Jr. (1987). Identification and regulation of a gene required for cell fusion during mating of the yeast Saccharomyces cerevisiae. Molecular and cellular biology 7, 2680-2690.

McClure, A.W., Wu, C.-F., Johnson, S.A., and Lew, D.J. (2016). Imaging Polarization in Budding Yeast. Methods in molecular biology (Clifton, N.J.) 1407, 13-23.

McCormack, J., Welsh, N.J., and Braga, V.M. (2013). Cycling around cell-cell adhesion with Rho GTPase regulators. Journal of cell science 126, 379-391.

Meitinger, F., Khmelinskii, A., Morlot, S., Kurtulmus, B., Palani, S., Andres-Pons, A., Hub, B., Knop, M., Charvin, G., and Pereira, G. (2014). A memory system of negative polarity cues prevents replicative aging. Cell 159, 1056-1069.

Meitinger, F., Richter, H., Heisel, S., Hub, B., Seufert, W., and Pereira, G. (2013). A safeguard mechanism regulates Rho GTPases to coordinate cytokinesis with the establishment of cell polarity. PLoS biology 11, e1001495.

Miller, K.E., Lo, W.-C., Lee, M.E., Kang, P.J., and Park, H.-O. (2017). Fine-tuning the orientation of the polarity axis by Rga1, a Cdc42 GTPase-activating protein. Molecular biology of the cell 28, 3773-3788.

Miller, K.E., Lo, W.C., Chou, C.S., and Park, H.O. (2019). Temporal regulation of cell polarity via the interaction of the Ras GTPase Rsr1 and the scaffold protein Bem1. Mol Biol Cell, mbcE19020106.

Moran, K.D., Kang, H., Araujo, A.V., Zyla, T.R., Saito, K., Tsygankov, D., and Lew, D.J. (2019). Cell-cycle control of cell polarity in yeast. The Journal of Cell Biology 218, 171.

Mosch, H.U., Kubler, E., Krappmann, S., Fink, G.R., and Braus, G.H. (1999). Crosstalk between the Ras2p-controlled mitogen-activated protein kinase and cAMP pathways during invasive growth of Saccharomyces cerevisiae. Molecular biology of the cell 10, 1325-1335.

Mosch, H.U., Roberts, R.L., and Fink, G.R. (1996). Ras2 signals via the Cdc42/Ste20/mitogen-activated protein kinase module to induce filamentous growth in Saccharomyces cerevisiae. Proceedings of the National Academy of Sciences of the United States of America 93, 5352-5356.

Nern, A., and Arkowitz, R.A. (2000). G proteins mediate changes in cell shape by stabilizing the axis of polarity. Molecular cell 5, 853-864.

Nishimura, A., Yamamoto, K., Oyama, M., Kozuka-Hata, H., Saito, H., and Tatebayashi, K. (2016). Scaffold Protein Ahk1, Which Associates with Hkr1, Sho1, Ste11, and Pbs2, 
Inhibits Cross Talk Signaling from the Hkr1 Osmosensor to the Kss1 Mitogen-Activated Protein Kinase. Molecular and cellular biology 36, 1109-1123. Noguchi, S., Saito, A., and Nagase, T. (2018). YAP/TAZ Signaling as a Molecular Link between Fibrosis and Cancer. International journal of molecular sciences 19. Daughter cell identity emerges from the interplay of Cdc42, septins, and exocytosis. Developmental cell 26, 148-161. Dynamics in Budding Yeast Using a Biosensor. Methods in enzymology 589, 171-190. detection of mitochondria-associated protein interactions. Methods in molecular biology (Clifton, N.J.) 1264, 395-419. domain fluorescence lifetime imaging microscopy: a quantitative method to follow transient protein-protein interactions in living cells. Cold Spring Harbor protocols 2015, 508-521.

Pan, X., Harashima, T., and Heitman, J. (2000). Signal transduction cascades regulating pseudohyphal differentiation of Saccharomyces cerevisiae. Current opinion in microbiology 3, 567-572. regulation of metabolic reprogramming. Oncogene 38, 2223-2240.

Pei, D., Shu, X., Gassama-Diagne, A., and Thiery, J.P. (2019). Mesenchymal-epithelial transition in development and reprogramming. Nat Cell Biol 21, 44-53.

Periasamy, A., and Clegg, R.M. (2009). FLIM microscopy in biology and medicine. CRC Press.

Peter, M., Neiman, A.M., Park, H.O., van Lohuizen, M., and Herskowitz, I. (1996). Functional analysis of the interaction between the small GTP binding protein Cdc42 and the Ste20 protein kinase in yeast. The EMBO journal 15, 7046-7059. visualized experiments : JoVE.

Piroli, M.E., Blanchette, J.O., and Jabbarzadeh, E. (2019). Polarity as a physiological modulator of cell function. Frontiers in bioscience (Landmark edition) 24, 451-462.

Pitoniak, A., Birkaya, B., Dionne, H.M., Vadaie, N., and Cullen, P.J. (2009). The signaling mucins Msb2 and Hkr1 differentially regulate the filamentation mitogenactivated protein kinase pathway and contribute to a multimodal response. Molecular biology of the cell 20,3101-3114.

Pitoniak, A., Chavel, C.A., Chow, J., Smith, J., Camara, D., Karunanithi, S., Li, B., Wolfe, K.H., and Cullen, P.J. (2015). Cdc42p-Interacting Protein Bem4p Regulates the Filamentous-Growth Mitogen-Activated Protein Kinase Pathway. Molecular and cellular biology 35, 417-436.

1180 Pringle, J.R., Bi, E., Harkins, H.A., Zahner, J.E., De Virgilio, C., Chant, J., Corrado, K., and Fares, H. (1995). Establishment of cell polarity in yeast. Cold Spring Harbor science 113 ( Pt 4), 571-585. 
Pruyne, D., and Bretscher, A. (2000b). Polarization of cell growth in yeast. I. Establishment and maintenance of polarity states. Journal of cell science 113 ( Pt 3), 365375. MAPKs. Oncogene 26, 3100-3112. homologs in Saccharomyces cerevisiae function in S phase and in G2. Genes Dev 6, 2021-2034.

Richman, T.J., and Johnson, D.I. (2000). Saccharomyces cerevisiae cdc42p GTPase is involved in preventing the recurrence of bud emergence during the cell cycle. Molecular and cellular biology 20, 8548-8559.

Roberts, C.J., Nelson, B., Marton, M.J., Stoughton, R., Meyer, M.R., Bennett, H.A., He, Y.D., Dai, H., Walker, W.L., Hughes, T.R., Tyers, M., Boone, C., and Friend, S.H. (2000). Signaling and circuitry of multiple MAPK pathways revealed by a matrix of global gene expression profiles. Science 287, 873-880. Roberts, R.L., and Fink, G.R. (1994). Elements of a single MAP kinase cascade in Saccharomyces cerevisiae mediate two developmental programs in the same cell type: mating and invasive growth. Genes \& development 8, 2974-2985.

Rose, M.D., Winston, F., and Hieter, P. (1990). Methods in yeast genetics. Cold Spring Harbor Laboratory Press, Cold Spring Harbor, NY.

Rupp, S., Summers, E., Lo, H.J., Madhani, H., and Fink, G. (1999). MAP kinase and cAMP filamentation signaling pathways converge on the unusually large promoter of the yeast FLO11 gene. The EMBO journal 18, 1257-1269.

Sabbagh, W., Jr., Flatauer, L.J., Bardwell, A.J., and Bardwell, L. (2001). Specificity of MAP kinase signaling in yeast differentiation involves transient versus sustained MAPK activation. Molecular cell 8, 683-691.

1211 Raunser, S. (2013). The role of Cdc42 and Gicl in the regulation of septin filament formation and dissociation. eLife 2, e01085.

Saito, H. (2010). Regulation of cross-talk in yeast MAPK signaling pathways. Current opinion in microbiology 13, 677-683.

Sambrook, J., Fritsch, E.F., and Maniatis, T. (1989). Molecular cloning: a laboratory manual. Cold Spring Harbor Laboratory Press, Cold Spring Harbor, NY.

Schneider, B.L., Seufert, W., Steiner, B., Yang, Q.H., and Futcher, A.B. (1995). Use of polymerase chain reaction epitope tagging for protein tagging in Saccharomyces cerevisiae. Yeast 11, 1265-1274.

Sherer, L.A., Zweifel, M.E., and Courtemanche, N. (2018). Dissection of two parallel pathways for formin-mediated actin filament elongation. J Biol Chem 293, 17917-17928.

Si, H., Rittenour, W.R., and Harris, S.D. (2016). Roles of Aspergillus nidulans Cdc42/Rho GTPase regulators in hyphal morphogenesis and development. Mycologia 108, 543-555.

Sikorski, R.S., and Hieter, P. (1989). A system of shuttle vectors and yeast host strains designed for efficient manipulation of DNA in Saccharomyces cerevisiae. Genetics 122, 19-27. 
Simon, M.N., De Virgilio, C., Souza, B., Pringle, J.R., Abo, A., and Reed, S.I. (1995). Role for the Rho-family GTPase Cdc42 in yeast mating-pheromone signal pathway. Nature 376, 702-705. number in individual Escherichia coli cells using single-molecule fluorescent in situ hybridization. Nature protocols 8, 1100-1113.

Smith, G.R., Givan, S.A., Cullen, P., and Sprague, G.F., Jr. (2002). GTPase-activating proteins for Cdc42. Eukaryotic cell 1, 469-480.

Smith, S.E., Rubinstein, B., Mendes Pinto, I., Slaughter, B.D., Unruh, J.R., and Li, R. (2013). Independence of symmetry breaking on Bem1-mediated autocatalytic activation of Cdc42. The Journal of cell biology 202, 1091-1106. Sopko, R., Huang, D., Preston, N., Chua, G., Papp, B., Kafadar, K., Snyder, M., Oliver, S.G., Cyert, M., Hughes, T.R., Boone, C., and Andrews, B. (2006). Mapping pathways and phenotypes by systematic gene overexpression. Mol Cell 21, 319-330.

Spellman, P.T., Sherlock, G., Zhang, M.Q., Iyer, V.R., Anders, K., Eisen, M.B., Brown, P.O., Botstein, D., and Futcher, B. (1998). Comprehensive identification of cell cycleregulated genes of the yeast Saccharomyces cerevisiae by microarray hybridization. Molecular biology of the cell 9, 3273-3297.

Stevenson, B.J., Rhodes, N., Errede, B., and Sprague, G.F., Jr. (1992). Constitutive mutants of the protein kinase STE11 activate the yeast pheromone response pathway in the absence of the G protein. Genes \& development 6, 1293-1304.

Sun, Y., Day, R.N., and Periasamy, A. (2011). Investigating protein-protein interactions in living cells using fluorescence lifetime imaging microscopy. Nature protocols $6,1324-$ 1340.

Sun, Y., and Periasamy, A. (2015). Localizing protein-protein interactions in living cells using fluorescence lifetime imaging microscopy. Methods in molecular biology (Clifton, N.J.) 1251, 83-107.

Taciak, B., Pruszynska, I., Kiraga, L., Bialasek, M., and Krol, M. (2018). Wnt signaling pathway in development and cancer. Journal of physiology and pharmacology : an official journal of the Polish Physiological Society 69.

Taheri, N., Kohler, T., Braus, G.H., and Mosch, H.U. (2000). Asymmetrically localized Bud8p and Bud9p proteins control yeast cell polarity and development. The EMBO journal 19, 6686-6696.

Takahashi, S., and Pryciak, P.M. (2007). Identification of novel membrane-binding domains in multiple yeast Cdc42 effectors. Molecular biology of the cell 18, 4945-4956.

Tatebayashi, K., Tanaka, K., Yang, H.Y., Yamamoto, K., Matsushita, Y., Tomida, T., Imai, M., and Saito, H. (2007). Transmembrane mucins Hkr1 and Msb2 are putative osmosensors in the SHO1 branch of yeast HOG pathway. The EMBO journal 26, 35213533.

Tatebayashi, K., Yamamoto, K., Tanaka, K., Tomida, T., Maruoka, T., Kasukawa, E., and Saito, H. (2006). Adaptor functions of Cdc42, Ste50, and Sho1 in the yeast osmoregulatory HOG MAPK pathway. The EMBO journal 25, 3033-3044.

Tong, Z., Gao, X.D., Howell, A.S., Bose, I., Lew, D.J., and Bi, E. (2007). Adjacent positioning of cellular structures enabled by a Cdc42 GTPase-activating protein-mediated zone of inhibition. The Journal of cell biology 179, 1375-1384. 
1274 Vadaie, N., Dionne, H., Akajagbor, D.S., Nickerson, S.R., Krysan, D.J., and Cullen, P.J. (2008). Cleavage of the signaling mucin Msb2 by the aspartyl protease Yps1 is required for MAPK activation in yeast. The Journal of cell biology 181, 1073-1081. van der Felden, J., Weisser, S., Bruckner, S., Lenz, P., and Mosch, H.U. (2014). The transcription factors Tec1 and Ste12 interact with coregulators Msa1 and Msa2 to activate adhesion and multicellular development. Molecular and cellular biology 34, 2283-2293. Venters, B.J., Wachi, S., Mavrich, T.N., Andersen, B.E., Jena, P., Sinnamon, A.J., Jain, P., Rolleri, N.S., Jiang, C., Hemeryck-Walsh, C., and Pugh, B.F. (2011). A comprehensive genomic binding map of gene and chromatin regulatory proteins in Saccharomyces. Molecular cell 41, 480-492.

Wasch, R., and Cross, F.R. (2002). APC-dependent proteolysis of the mitotic cyclin Clb2 is essential for mitotic exit. Nature 418, 556-562.

Wedlich-Soldner, R., Altschuler, S., Wu, L., and Li, R. (2003). Spontaneous cell polarization through actomyosin-based delivery of the Cdc42 GTPase. Science 299, 1231-1235.

Wedlich-Soldner, R., Wai, S.C., Schmidt, T., and Li, R. (2004). Robust cell polarity is a dynamic state established by coupling transport and GTPase signaling. The Journal of cell biology 166, 889-900.

Winkler, A., Arkind, C., Mattison, C.P., Burkholder, A., Knoche, K., and Ota, I. (2002). Heat stress activates the yeast high-osmolarity glycerol mitogen-activated protein kinase pathway, and protein tyrosine phosphatases are essential under heat stress. Eukaryotic cell 1, 163-173.

Wittenberg, C., and Reed, S.I. (2005). Cell cycle-dependent transcription in yeast: promoters, transcription factors, and transcriptomes. Oncogene 24, 2746-2755.

Woods, B., and Lew, D.J. (2019). Polarity establishment by Cdc42: Key roles for positive feedback and differential mobility. Small GTPases 10, 130-137.

$\mathrm{Wu}, \mathrm{X}$., and Jiang, Y.W. (2005). Possible integration of upstream signals at Cdc42 in filamentous differentiation of S. cerevisiae. Yeast 22, 1069-1077.

Wu, X., Quondamatteo, F., Lefever, T., Czuchra, A., Meyer, H., Chrostek, A., Paus, R., Langbein, L., and Brakebusch, C. (2006). Cdc42 controls progenitor cell differentiation and beta-catenin turnover in skin. Genes \& development 20, 571-585.

Yang, L., Wang, L., Geiger, H., Cancelas, J.A., Mo, J., and Zheng, Y. (2007). Rho GTPase Cdc42 coordinates hematopoietic stem cell quiescence and niche interaction in the bone marrow. Proceedings of the National Academy of Sciences of the United States of America 104, 5091-5096.

Yoon, S., and Seger, R. (2006). The extracellular signal-regulated kinase: multiple substrates regulate diverse cellular functions. Growth factors (Chur, Switzerland) 24, 21 44.

Yuzyuk, T., and Amberg, D.C. (2003). Actin recovery and bud emergence in osmotically stressed cells requires the conserved actin interacting mitogen-activated protein kinase kinase kinase Ssk2p/MTK1 and the scaffold protein Spa2p. Molecular biology of the cell 14, 3013-3026.

Zanelli, C.F., and Valentini, S.R. (2005). Pkc1 acts through Zds1 and Gic1 to suppress growth and cell polarity defects of a yeast eIF5A mutant. Genetics 171, 1571-1581. 
1318 Zarrinpar, A., Bhattacharyya, R.P., Nittler, M.P., and Lim, W.A. (2004). Sho1 and Pbs2 1319 Act as Coscaffolds Linking Components in the Yeast High Osmolarity MAP Kinase 1320 Pathway. Molecular cell 14, 825-832.

1321 Zihni, C., and Terry, S.J. (2015). RhoGTPase signalling at epithelial tight junctions: 1322 Bridging the GAP between polarity and cancer. The international journal of biochemistry 1323 \& cell biology 64, 120-125. 
MAPK Pathway Regulates Bud Emergence

Prabhakar et al.

\section{FIGURE LEGENDS}

\section{Figure 1. Role of the fMAPK pathway in rescue of the growth defect of the $c d c 24-4$}

1327 mutant. (A) Pathways that regulate bud emergence (green) and filamentous growth

1328 (blue). Cdc $24 p$ and Cdc42p regulate both pathways. Not all proteins are shown. (B)

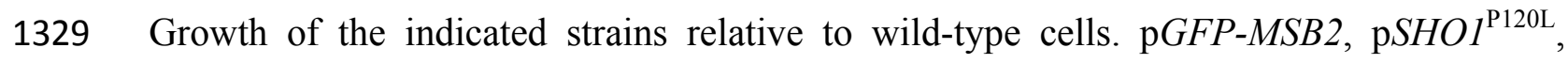

$1330 \mathrm{pSTE} 11-4$ and pTEF2-GIC2 were expressed from plasmids (see Table 2). Error bars show

1331 the standard error of the mean from three separate trials. Asterisk, p-value $<0.01$. CTL,

1332 plasmid pRS316. (C) Growth of strains relative to $c d c 24-4$. This experiment was

1333 performed in galactose (GAL) media, which also compromised the viability of the $c d c 24$ -

13344 mutant, because the pbs $2 \Delta$ mutant has a growth defect at $37^{\circ} \mathrm{C}$ (Winkler et al., 2002).

1335 (D) Inverted maximum intensity projection of GFP-Cdc42p localization in the indicated

1336 strains, examined after incubation at $37^{\circ} \mathrm{C}$ for $4 \mathrm{~h}$. Asterisks point to GFP-Cdc42p

1337 clustering. Arrows, sites of bud emergence. Bar, 5 microns. (E) Quantification of GFP-

1338 Cdc42p clustering. Error bars represent standard error of mean for three separate trials. 50

1339 cells were counted in each trial. Asterisk, p-value $<0.05$. (F) Cdc12p-GFP localization in

1340 the indicated strains, examined after incubation at $37^{\circ} \mathrm{C}$ for $4 \mathrm{~h}$. Arrows, Cdc $12 \mathrm{p}-\mathrm{GFP}$

1341 localization in incipient buds; asterisk, Cdc12p-GFP localization at mother-bud neck in

1342 growing bud; arrowheads, mislocalized Cdc12p-GFP. Bar, 5 microns. (G) Quantification

1343 of septin localization. Error bars represent standard error of mean for three separate trials.

134450 cells were counted in each trial. Asterisk, p-value $<0.05$. 
1347 bud emergence. (A) Localization of Gic2p-PBD-tdTomato in wild-type cells and the

1348 tecls mutant under the indicated conditions. Micrographs were taken at the same

1349 exposure. Bar, 7.5 microns. (B) Quantitation of normalized total pixel intensity of Gic2p-

1350 PBD-tdTomato cluster in wild-type and tec1s mutant cells. Error bars represent

1351 standard error of mean of over 60 cells. Asterisk, p-value $<0.00001$. (C) Wild-type cells

1352 expressing plasmid-borne Cdc42p biosensors and combinations of $M S B 2^{\Delta 100-818}$

1353 examined by FLIM-FRET microscopy. In a separate experiment, wild type and the gicl $\Delta$

1354 gic $2 \Delta$ double mutant expressing the wild-type Cdc42p biosensor were grown to mid-log

1355 and shifted to $37^{\circ} \mathrm{C}$ for $4 \mathrm{~h}$ followed by examination by FLIM-FRET microscopy. Each

1356 histogram represents the mean of a set of measurements from three independent trials.

1357 The average of $>15$ cells is reported for each strain. Error bars represent the standard

1358 error of mean. Asterisk, p-value $<0.05$. N.S., not significant.

dormant sites. (A) Immunoblot analysis of wild-type cells synchronized in $\mathrm{G}_{1}$ by $\alpha$ -

1362 factor arrest and released in YEPD. Cell extracts were probed at indicated time points

1363 with antibodies to Clb2p-HA ( $\alpha-\mathrm{HA}), \mathrm{P} \sim \mathrm{Kss} 1 \mathrm{p}(\alpha-\mathrm{p} 44 / 42)$, and Pgk1p, as a control for

1364 protein levels. Numbers refer to the ratio of $\mathrm{P} \sim \mathrm{Kss} 1 \mathrm{p}$ to Pgk1p relative to 0 min, which

1365 was set to 1 . BE, bud emergence. (B) Same as panel A, except cells were released into

1366 YEP-GAL media. (C) Immunoblot analysis of wild type and mutant combinations to

1367 assess fMAPK pathway activity. Pgk1p, loading control. Numbers refer to the ratio of

$1368 \mathrm{P} \sim \mathrm{Kss} 1 \mathrm{p}$ to Pgk1p relative to wild type, set to 1 (D) Immunoblot analysis of the role of 
MAPK Pathway Regulates Bud Emergence

Prabhakar et al.

1369

1370

1371

1372

1373

1374

1375

1376

1377

1378

1379

1380

1381

1382

1383

1384

1385

1386

1387

1388

1389

1390

1391

Msb2p in regulating the elevated fMAPK pathway activity in mutants lacking the negative polarity complex. See panel $3 \mathrm{C}$ for details.

\section{Figure 4. Role of the fMAPK pathway in regulating bud emergence during}

filamentous growth. (A) Inverted maximum intensity projection of GFP-Cdc42p clustering and bud emergence in wild-type cells in GAL. Cdc3p-mCherry was used as a marker for cell cycle progression. Septin hourglass split into double ring was set as time 0. Green arrowheads, first visible cluster of GFP-Cdc42p. Red arrowheads, recruitment of Cdc3p-mCherry at incipient site. Arrows, bud emergence. Graph represents GFP$\mathrm{Cdc} 42 \mathrm{p}$ intensity over time measured as coefficient of variance $(\mathrm{CV})$ of pixel intensity of the entire cell. Arrow, timing of bud emergence. Bar, 5 microns. m, mother cell; d, daughter cell. (B) Quantitation of the timing of GFP-Cdc42p clustering, Cdc3p-mCherry recruitment and bud emergence in wild-type cells and ste $12 \Delta$ cells grown on semi-solid S-GAL-URA media. Average of 17 cells for each strain is reported. Error bar represent standard error of mean. Asterisk, p-value $<0.05$. (C) Same as A, except ste12 $\Delta$ mutant. (D) Same as $\mathrm{C}$, except $\mathrm{t}=0$ represents start of experiment. Time points for the preceding cell cycle were not available for this cell. (E) Same as A, except tec $1 \Delta$ mutant. (F) Percent cells showing transient appearance and disappearance of polarity complex detected by co-localization of GFP-Cdc42p and Cdc3p-mCherry in cells from B. Error bar represents standard error of mean of 17 cells. Asterisk, p-value $<0.01$. (G) GFPCdc42p intensity over time measured as pixel intensity $\mathrm{CV}$ for indicated strains. The average of 17 cells is reported for each strain. Error bars represent the standard error of mean. 
MAPK Pathway Regulates Bud Emergence

Prabhakar et al.

1393 Figure 5. Role of the fMAPK pathway in making multiple growth sites. (A) S.E.M

1394 images of wild type and $M S B 2^{\Delta 100-818}$ examined for multiple growth sites. Bar, 5 microns.

1395 (B) Comparison of percentage of multiple growth sites by the single cell assay to

$1396 \mathrm{P} \sim \mathrm{Kss} 1 \mathrm{p}$ levels in panel $\mathrm{C}$ in the indicated strains. Error bars represent standard error of

1397 mean from three separate trials. Over 50 cells were counted in each trial. The histogram

1398 for $\mathrm{P} \sim \mathrm{Kss} 1 \mathrm{p}$ represents the ratio of $\mathrm{P} \sim \mathrm{Kss} 1 \mathrm{p}$ to $\mathrm{Pgk} 1 \mathrm{p}$ relative to wild type, which was

1399 set to 1. (C) Immunoblot analysis of fMAPK activity in the indicated strains grown in

1400 YEP-GAL. Pgk1p, loading control. Numbers refer to the ratio of P Kss 1p to Pgk1p

1401 relative to wild type, which was set to 1 . (D) Percentage of multiple buds by the single

1402 cell assay in indicated strains. In a separate experiment, wild-type cells expressing TEF2-

1403 GIC2 were grown to saturation and evaluated for the percentage of multiple buds. See

1404 panel B for details. Asterisk, p-value $<0.01$.

1406 Figure 6. Activation of the fMAPK pathway leads to wandering of polarity. (A)

1407 Wild-type cells and cells carrying $M S B 2^{\Delta 100-818}$ were examined on S-GLU media by the 1408 single cell invasive growth assay. Arrows indicate growth sites. Bar, 5 microns. (B) Wild 1409 type and $M S B 2^{\Delta 100-818}$ containing Cdc24p-GFP were examined by single cell invasive 1410 growth assay. Arrows points to Cdc24p-GFP at the growing tip. Scale bar, 5 microns. (C)

1411 At left, actin staining of cells by rhodamine phalloidin. Bar, 5 microns. Micrographs for $1412 M S B 2^{\Delta 100-818}$ shown at different focal planes in the Z-axis. At right, inverted maximum 1413 intensity projection of cell on left shown using red lookup table. (D) Time series of wild 
MAPK Pathway Regulates Bud Emergence

Prabhakar et al.

1414 type and $M S B 2^{\Delta 100-818}$ expressing GFP-Cdc42p evaluated for multiple growth sites. Bar, 5

1415 microns. Time interval; WT, $10 \mathrm{~min} ; M S B 2^{\Delta 100-818}, 20 \mathrm{~min}$. Highlighted regions were

1416 used to prepare kymographs in D. DIC and inverted maximum intensity projection

1417 shown. (E) Kymographs were prepared using ImageJ as described in materials and

1418 methods. Bar, 40 min. (F) SEM images of wild type and Cdc42p ${ }^{\text {V36T }}$. Scale bar, 5

1419 microns.

1421 Figure 7. Model for the regulation of bud emergence that involves cross-regulation

1422 between the polarity and the fMAPK pathways. Arrows, positive regulation; bar, negative 1423 regulation. 
bioRxiv preprint doi: https://doi.org/10.1101/786426; this version posted September 30, 2019. The copyright holder for this preprint (which was not certified by peer review) is the author/funder. All rights reserved. No reuse allowed without permission.

MAPK Pathway Regulates Bud Emergence

Prabhakar et al.

\section{TABLES}

1426 Table 1. Yeast strains used in the study.

\begin{tabular}{|c|c|c|}
\hline Name & Genotype & Reference \\
\hline $\mathrm{PC} 301^{\mathrm{a}}$ & MATa ura3-52 ste12::URA3 & (Cullen and Sprague, 2002) \\
\hline PC313 & MATa $u r a 3-52$ & (Liu et al., 1993) \\
\hline PC538 & MATa ste4 FUS1-lacZ FUS1-HIS3 ura3-52 & (Cullen et al., 2004) \\
\hline PC539 & MATa ste4 FUS1-lacZ FUS1-HIS3 ura3-52 ste12::URA3 & (Cullen et al., 2004) \\
\hline PC544 & MATa ste4 FUS1-lacZ FUS1-HIS3 ura3-52 bni1::KlURA3 ${ }^{\mathrm{b}}$ & (Cullen and Sprague, 2002) \\
\hline PC611 & MATa ste4 FUS1-lacZ FUS1-HIS3 ura3-52 ste11::KlURA3 & (Cullen et al., 2004) \\
\hline PC622 & MATa ste4 FUS1-lacZ FUS1-HIS3 ura3-52 GAL-SHO1::KanMX6 & (Cullen et al., 2004) \\
\hline PC948 & MATa ste4 FUS1-lacZ FUS1-HIS3 ura3-52 msb2::KanMX6 & (Cullen et al., 2004) \\
\hline PC1052 & $\begin{array}{l}\text { MATa ste4 FUS1-lacZ FUS1-HIS3 ura3-52 GAL-SHO1::KanMX6 } \\
\text { ste11::KlURA3 }\end{array}$ & This study \\
\hline PC1057 & MATa ste4 FUS1-lacZ FUS1-HIS3 ura3-52 ste11::URA3 & (Cullen and Sprague, 2002) \\
\hline PC1205 & MATa ste4 FUS1-lacZ FUS1-HIS3 ura3-52 CDC24-GFP::KanMX6 & (Vadaie et al., 2008) \\
\hline PC1512 & $\begin{array}{l}\text { MATa ste4 FUS1-lacZ FUS1-HIS3 ura3-52 CDC24-GFP::KanMX6 MSB2- } \\
\text { HA }\end{array}$ & This study \\
\hline PC1516 & MATa ste4 FUS1-lacZ FUS1-HIS3 ura3-52 MSB2-HA & (Cullen et al., 2004) \\
\hline PC1653 & $\begin{array}{l}\text { MATa ste4 FUS1-lacZ FUS1-HIS3 ura3-52 CDC24-GFP::HYG GAL- } \\
\text { SHO1::KanMX6 }\end{array}$ & This study \\
\hline PC1661 & NY64 MATa ura3-52 sec15-1 & (Finger and Novick, 2000) \\
\hline PC1806 & MATa ste4 FUS1-lacZ FUS1-HIS3 ura3-52 GAL-MSB2-HAA & This study \\
\hline PC1811 & MATa ste4 FUS1-lacZ FUS1-HIS3 ura3-52 MSB2-HA & (Vadaie et al., 2008) \\
\hline PC1837 & $\begin{array}{l}\text { MATa ste4 FUS1-lacZ FUS1-HIS3 ura3-52 GAL-MSB2-HA }{ }^{\Delta 100-818}:: \text { KanMX6 } \\
\text { ste12::KlURA3 }\end{array}$ & This study \\
\hline PC1894 & MATa ste4 FUS1-lacZ FUS1-HIS3 ura3-52 leu2::HYG & (Vadaie et al., 2008) \\
\hline PC2538 & MATa ste4 FUS1-lacZ FUS1-HIS3 ura3-52 leu2::HYG STE11-4::URA3 & (Chavel et al., 2010) \\
\hline PC2710 & MATa ste4 FUS1-lacZ FUS1-HIS3 ura3-52 cdc12-6::NAT & (Basu et al., 2016) \\
\hline PC2744 & MATa ste4 FUS1-lacZ FUS1-HIS3 ura3-52 CLB2-HA & This study \\
\hline PC4248 & MATa ste4 FUS1-lacZ FUS1-HIS3 ura3-52 rax2:: KanMX6 & (Basu et al., 2016) \\
\hline PC6077 & $\begin{array}{l}\text { MATa ste4 FUS1-lacZ FUS1-HIS3 ura3-52 leu2::HYG cdc24::NAT pRS315 } \\
\text { cdc24-4 }\end{array}$ & (Pitoniak et al., 2015) \\
\hline PC6627 & MATa ura3-52 Yip211 GIC2-PBD-tdTomato & $\begin{array}{l}\text { (Basu et al., UNDER } \\
\text { REVIEW) }\end{array}$ \\
\hline PC6810 & MATa ura3-52 leu2 ssk1 & $\begin{array}{l}\text { (Basu et al., UNDER } \\
\text { REVIEW) }\end{array}$ \\
\hline PC6932 & MATa ste4 FUS1-lacZ FUS1-HIS3 ura3-52 gps $1::$ KlURA3 & This study \\
\hline PC6936 & MATa ste4 FUS1-lacZ FUS1-HIS3 ura3-52 leu2::HYG cdc24 pRS315 cdc24-4 & This study \\
\hline PC6958 & $\begin{array}{l}\text { MATa ste4 FUS1-lacZ FUS1-HIS3 ura3-52 leu2::HYG cdc24 pRS315 cdc24-4 } \\
\text { ste12::NAT }\end{array}$ & This study \\
\hline PC6969 & $\begin{array}{l}\text { MATa ste4 FUS1-lacZ FUS1-HIS3 ura3-52 leu2::HYG cdc24 pRS315 cdc24-4 } \\
\text { cln1::NAT }\end{array}$ & This study \\
\hline PC7000 & MATa ste4 FUS1-lacZ FUS1-HIS3 ura3-52 msb2::KanMX6 nba1::KlURA3 & This study \\
\hline PC7002 & MATa ste4 FUS1-lacZ FUS1-HIS3 ura3-52 msb2::KanMX6 gps1::KlURA3 & This study \\
\hline PC7012 & $\begin{array}{l}\text { MATa ste4 FUS1-lacZ FUS1-HIS3 ura3-52 leu2::HYG cdc24 pRS315 cdc24-4 } \\
\text { rsr1::NAT }\end{array}$ & This study \\
\hline PC7018 & $\begin{array}{l}\text { MATa ste4 FUS1-lacZ FUS1-HIS3 ura3-52 leu2::HYG cdc24 pRS315 cdc24-4 } \\
\text { bnil::NAT }\end{array}$ & This study \\
\hline PC7020 & $\begin{array}{l}\text { MATa ste4 FUS1-lacZ FUS1-HIS3 ura3-52 leu2::HYG cdc24 pRS315 cdc24-4 } \\
\text { pbs2::NAT }\end{array}$ & This study \\
\hline PC7022 & $\begin{array}{l}\text { MATa ste4 FUS1-lacZ FUS1-HIS3 ura3-52 leu2::HYG cdc24 pRS315 cdc24-4 } \\
\text { bud8::NAT }\end{array}$ & This study \\
\hline PC7034 & MATa ste4 FUS1-lacZ FUS1-HIS3 ura3-52 gic1::KanMX6 & This study \\
\hline PC7036 & $\begin{array}{l}\text { MATa ste4 FUS1-lacZ FUS1-HIS3 ura3-52 leu2::HYG cdc24 pRS315 cdc24-4 } \\
\text { gic2::NAT }\end{array}$ & This study \\
\hline PC7040 & $\begin{array}{l}\text { MATa ste4 FUS1-lacZ FUS1-HIS3 ura3-52 leu2::HYG cdc24 pRS315 cdc24-4 } \\
\text { bud4::NAT }\end{array}$ & This study \\
\hline PC7043 & MATa ste4 FUS1-lacZ FUS1-HIS3 ura3-52 gic2::NAT & This study \\
\hline PC7044 & MATa ste4 FUS1-lacZ FUS1-HIS3 ura3-52 gic1::KanMX6 gic $2:: N A T$ & This study \\
\hline PC7046 & MATa ste4 FUS1-lacZ FUS1-HIS3 ura3-52 nba1::KanMX6 & This study \\
\hline PC7050 & MATa ura3-52 nba1::KanMX6 & This study \\
\hline PC7122 & $\begin{array}{l}\text { MATa ste4 FUS1-lacZ FUS1-HIS3 ura3-52 leu2::HYG cdc24 pRS315 cdc24-4 } \\
\text { flo11::NAT }\end{array}$ & This study \\
\hline PC7123 & MATa ste4 FUS1-lacZ FUS1-HIS3 ura3-52 gps $1::$ KanMX6 & \\
\hline PC7148 & $\begin{array}{l}\text { MATa ste4 FUS1-lacZ FUS1-HIS3 ura3-52 leu2::HYG cdc24 pRS315 cdc24-4 } \\
\text { tec1::NAT }\end{array}$ & This study \\
\hline PC7320 & MATa ura3-52 Yip211 GIC2-PBD-tdTomato tec1::NAT & This study \\
\hline
\end{tabular}


bioRxiv preprint doi: https://doi.org/10.1101/786426; this version posted September 30, 2019. The copyright holder for this preprint (which was not certified by peer review) is the author/funder. All rights reserved. No reuse allowed without permission.

MAPK Pathway Regulates Bud Emergence

Prabhakar et al.

$\begin{array}{ll}\text { PC7365 } & \text { MATa ura3-52 CDC3-mCherry:: HYG } \\ \text { PC7366 } & \text { MATa ura3-52 CDC3-mCherry::HYG ste 12::NAT } \\ \text { PC7367 } & \text { MATa ura3-52 CDC3-mCherry::HYG tecl }:: N A T \\ \text { PCV36T } & \text { MATa } \text { ura3-52 leu2 ssk1 CDC42 }\end{array}$
This study

This study

This study

(Basu et al., UNDER

REVIEW)

a. All strains are $\Sigma 1278$ b background unless otherwise indicated.

b. Kl, Kluyveromyces lactis. 
MAPK Pathway Regulates Bud Emergence

Prabhakar et al.

1430 Table 2. Plasmids used in the study. ${ }^{\text {a }}$

\begin{tabular}{|c|c|c|}
\hline Name & Description & Reference \\
\hline PC187 & YCp50-STE4 CEN/URA3 & (Stevenson et al., 1992) \\
\hline PC1333 & YCp50-STE11-4 & (Stevenson et al., 1992) \\
\hline PC1365 & YCplac181 CDC12-GFP & (Fares et al., 1996) \\
\hline PC1665 & $\mathrm{p} S E C 3-G F P$ & (Finger and Novick, 1997) \\
\hline PC1696 & $\mathrm{p} G F P-M S B 2$ & (Vadaie et al., 2008) \\
\hline PC1715 & pRS316-SHO1 $1^{\text {D16H P120L }}-G F P$ & (Vadaie et al., 2008) \\
\hline PC1885 & pMPY $-3 \times H A$ & (Schneider et al., 1995) \\
\hline PC1964 & pRS316-SHO1 ${ }^{\mathrm{D} 16 \mathrm{H}}-G F P$ & (Marles et al., 2004) \\
\hline PC2151 & pRS315 & (Sikorski and Hieter, 1989) \\
\hline PC2205 & pNAT & (Goldstein and McCusker, 1999) \\
\hline PC2206 & pHYG & (Goldstein and McCusker, 1999) \\
\hline PC2207 & pRS316 & (Sikorski and Hieter, 1989) \\
\hline PC6365 & YEp352-TEF2 & (Pitoniak et al., 2015) \\
\hline PC6454 & pRS316-GFP-linker-CDC42 & (Basu et al., UNDER REVIEW) \\
\hline PC6626 & Yip211 GIC2-PBD-tdTomato & (Okada et al., 2013) \\
\hline PC7082 & YEp352-TEF2-GIC2 & This study \\
\hline PC7137 & $\begin{array}{l}\mathrm{pRS} 316-\mathrm{p} A C T 1-E G F P-C R I B C L A 4- \\
C D C 42^{\triangle \mathrm{CAAX}}=\text { - } C \text { Cherry-CAAX }\end{array}$ & (Smith et al., 2013) \\
\hline PC7138 & $\begin{array}{l}\mathrm{pRS} 316-\mathrm{p} A C T 1-E G F P-C R I B C L A 4- \\
C D C 42^{\mathrm{Q} 61 \mathrm{~L} \triangle \mathrm{CAAX}}-m C h e r r y-C A A X\end{array}$ & (Smith et al., 2013) \\
\hline PC7139 & $\begin{array}{l}\mathrm{pRS} 316-\mathrm{p} A C T 1-E G F P-C R I B C L A 4- \\
C D C 42^{\mathrm{D} 57 \mathrm{Y} \triangle \mathrm{CAAX}}-m \text { Cherry-CAAX }\end{array}$ & (Smith et al., 2013) \\
\hline PC7143 & YCplac181 CDC12-GFP::KanMX6 & This study \\
\hline PC7150 & YCplac181 CDC12-GFP::NAT & This study \\
\hline PC7340 & pRS316-GFP-linker-CDC42::KanMX6 & This study \\
\hline PC7357 & pRS316-GFP-linker-CDC42::NAT & This study \\
\hline PC7359 & $\begin{array}{l}\text { pRS316-pACT1-EGFP-CRIBCLA4- } \\
C D C 42^{\Delta \mathrm{CAAX}}=\text {-mCherry-CAAX::KanMX6 }\end{array}$ & This study \\
\hline PC7361 & pRS316-SHO1 ${ }^{\mathrm{D} 16 \mathrm{H}}-G F P:: K a n M X 6$ & This study \\
\hline PC7363 & pRS316-SHO1 $1^{\mathrm{D} 16 \mathrm{H}}-G F P:: N A T$ & This study \\
\hline PC7381 & pRS315 cdc24-4 & (Pitoniak et al., 2015) \\
\hline
\end{tabular}

1431 a. The following plasmids were used from the movable ORF collection (Gelperin et al., 2005): $\mathrm{p} G A L-$ 1432 KIN3-HA, pGAL-LRE1-HA, pGAL-BET1-HA, pGAL-CLB4-HA, pGAL-YAP1801-HA, pGAL-YDL186W1433 HA, pGAL-DMA1-HA, pGAL-IQG1-HA, and $\mathrm{p} G A L-S T E 7-H A$. 
A
Budding Pathway

Axial (Axl2) + Distal (Bud8)

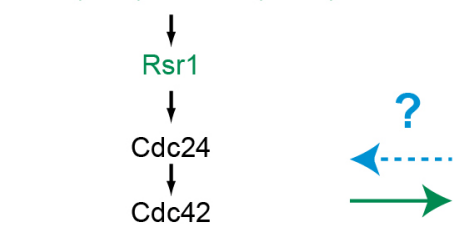

$\mathrm{Cla} 4_{\mathrm{Gic} 1+\mathrm{Gic} 2}^{\downarrow} \rightarrow \mathrm{Bni}$

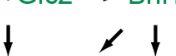

Septin Ring Actin t

Vesicle Delivery $\downarrow$

Bud Emergence
fMAPK Pathway

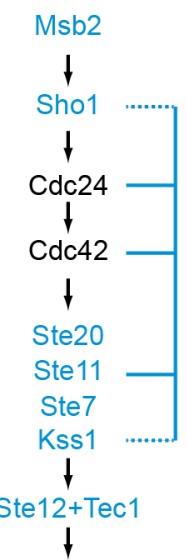

Filamentous Growth
B
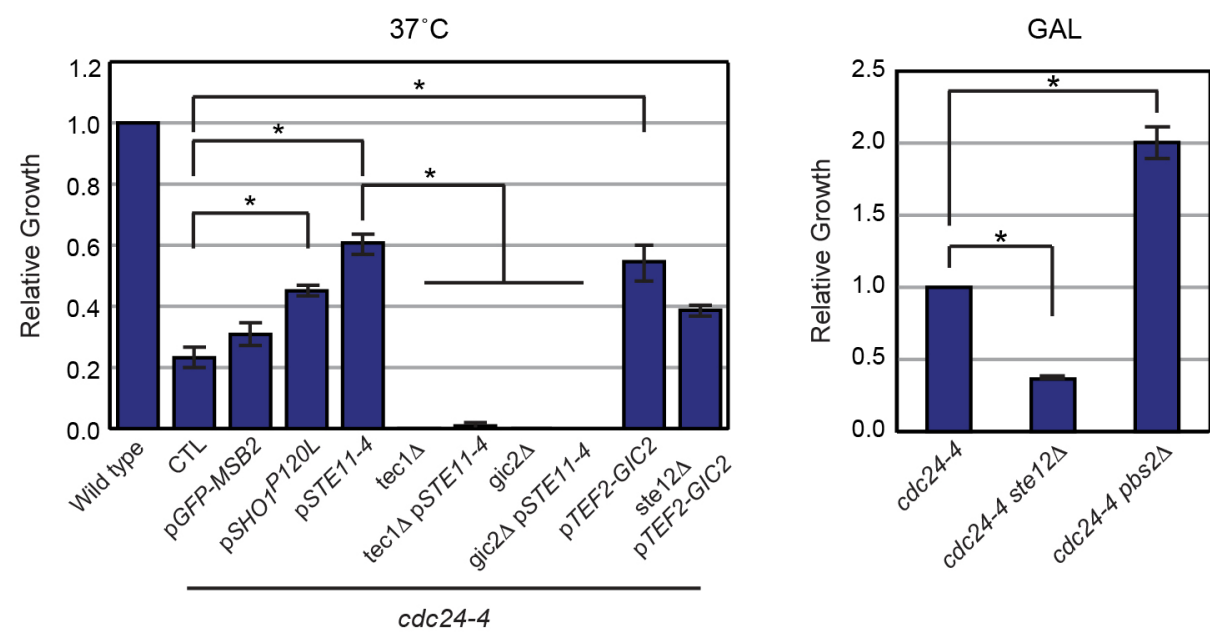

D

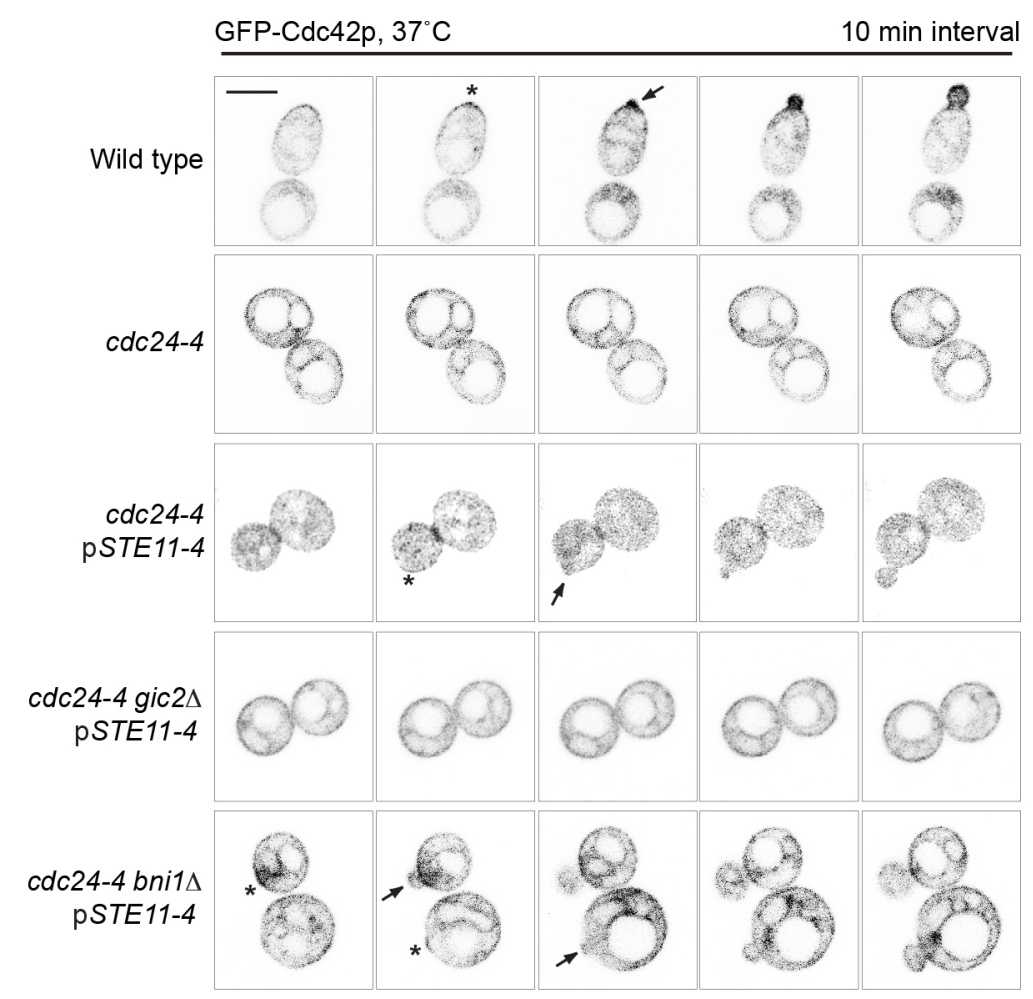

E

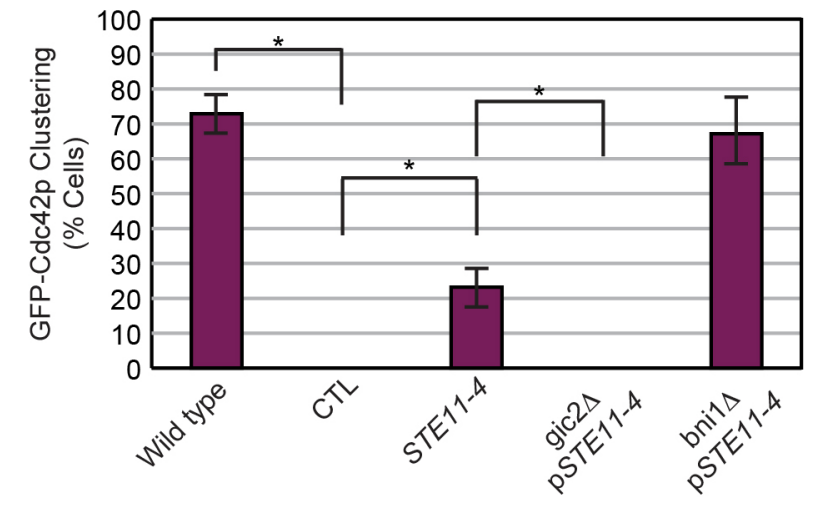

cdc24-4
$\mathbf{F}$

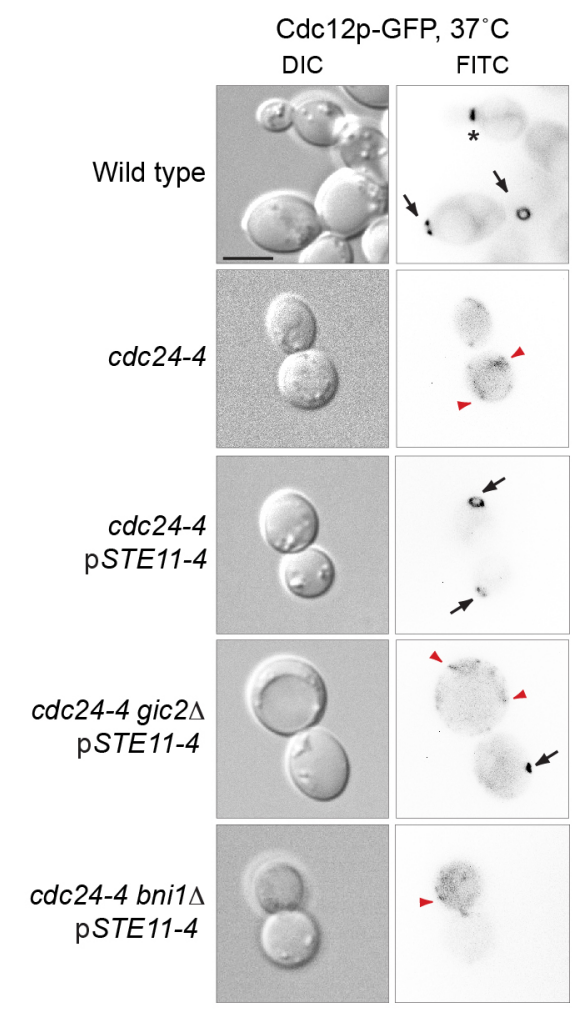

G

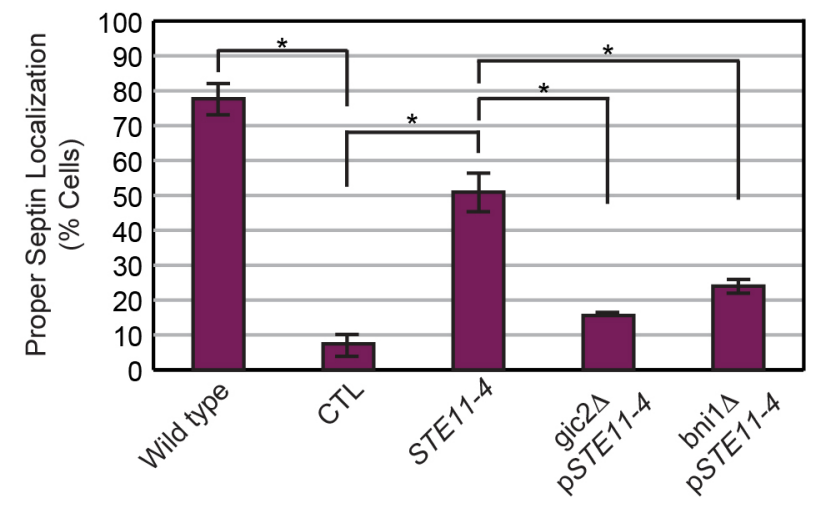


Fig._2
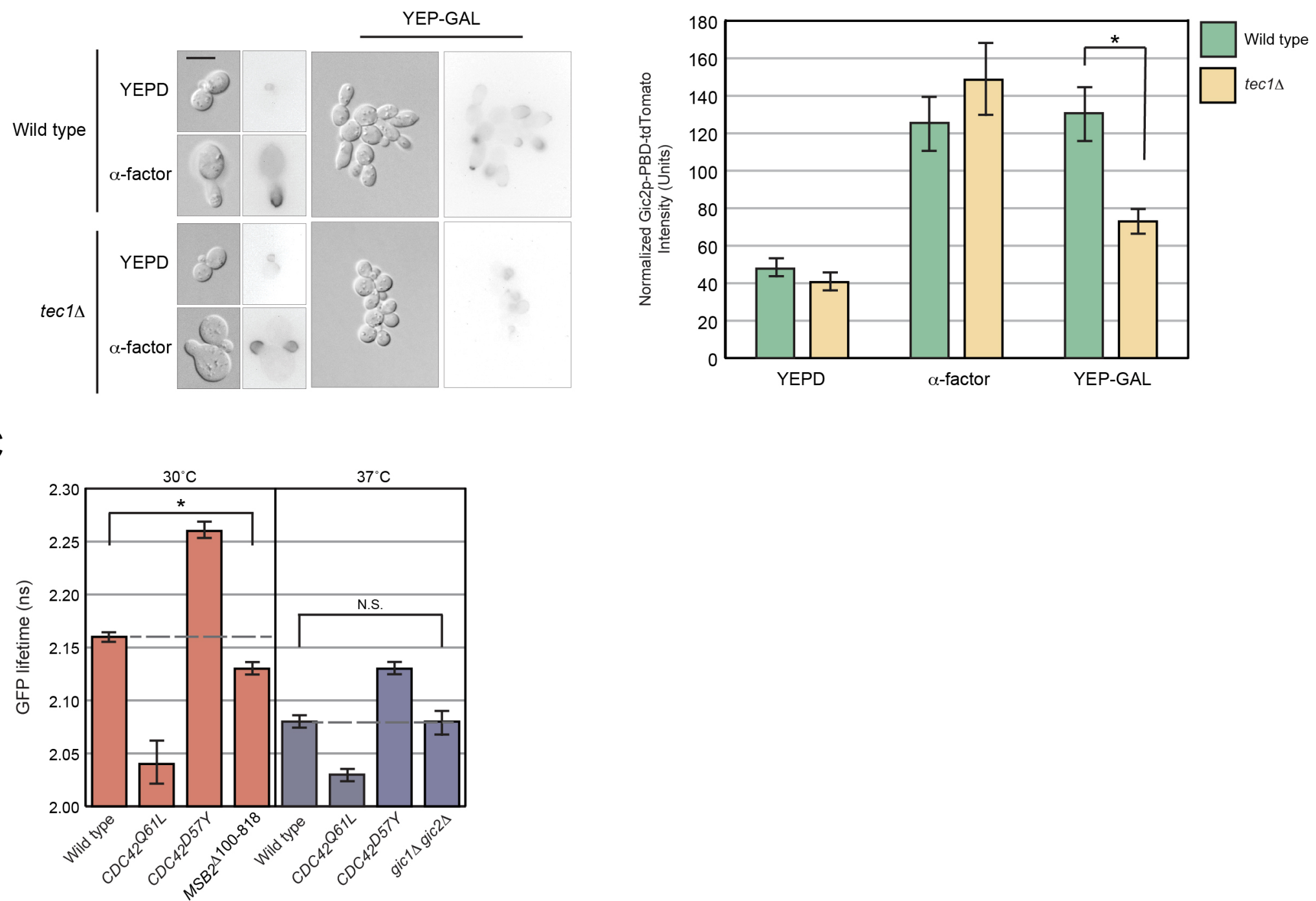


\section{YEPD}

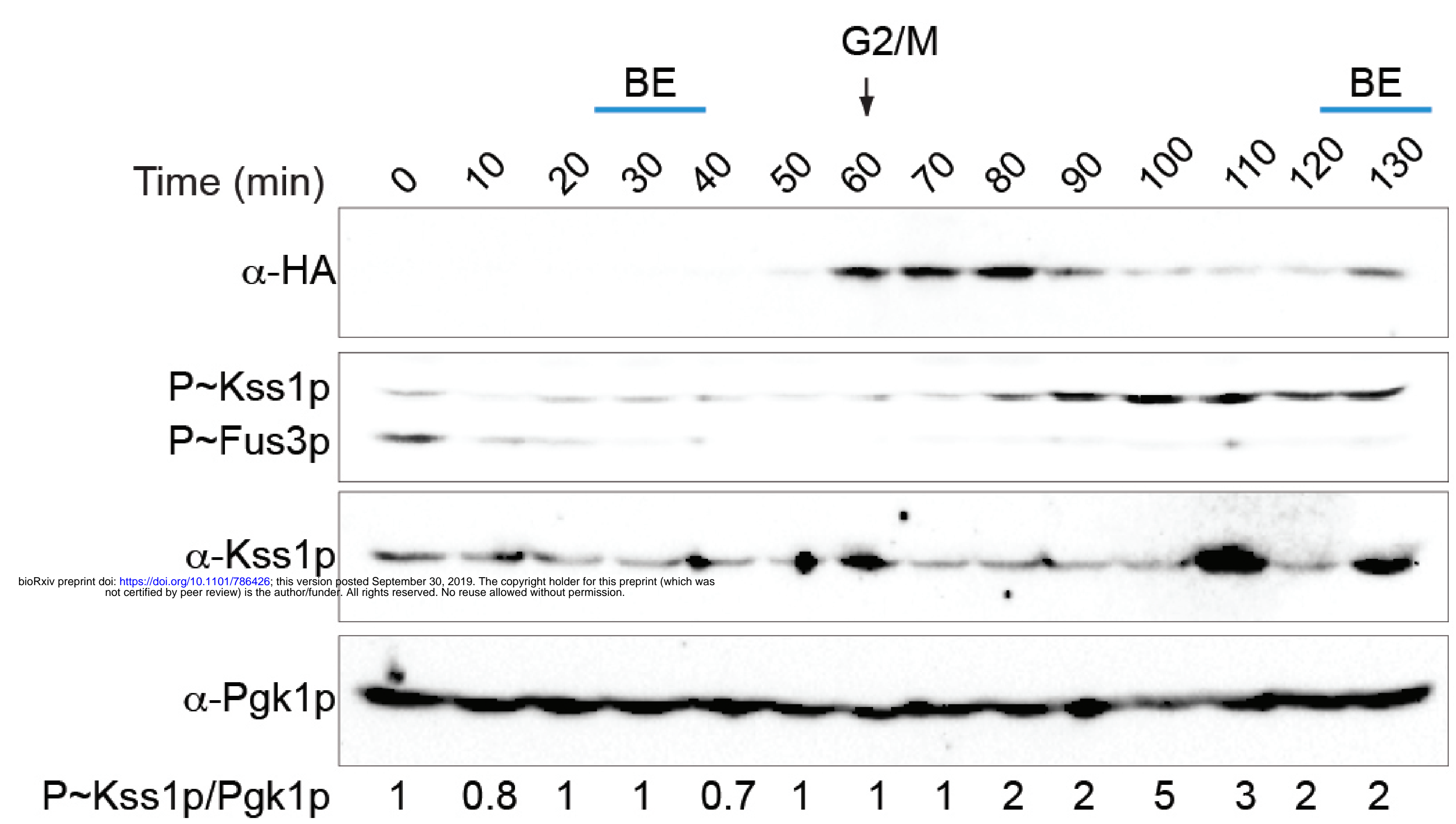

C

\section{B}

YEP-GAL




A

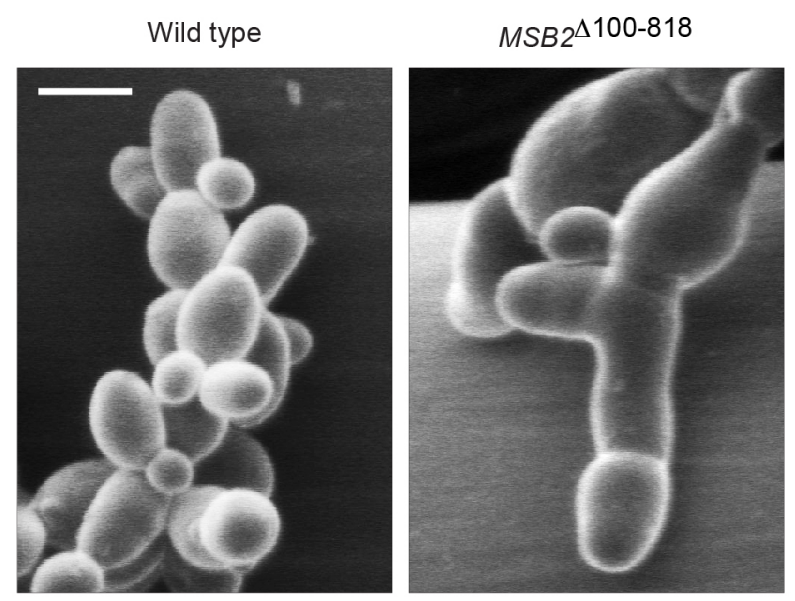

B

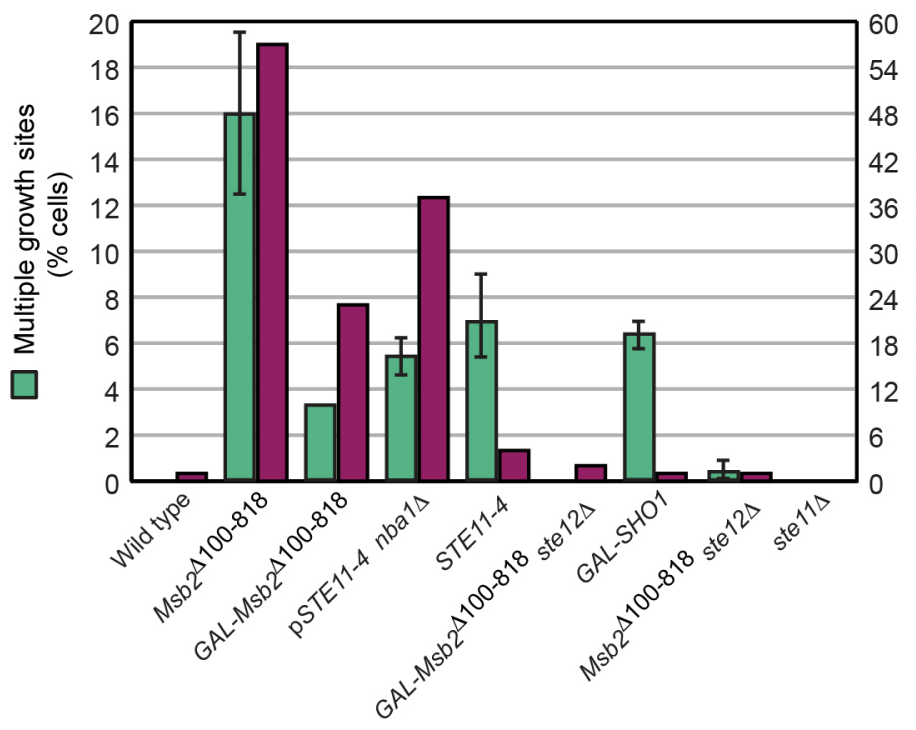

D

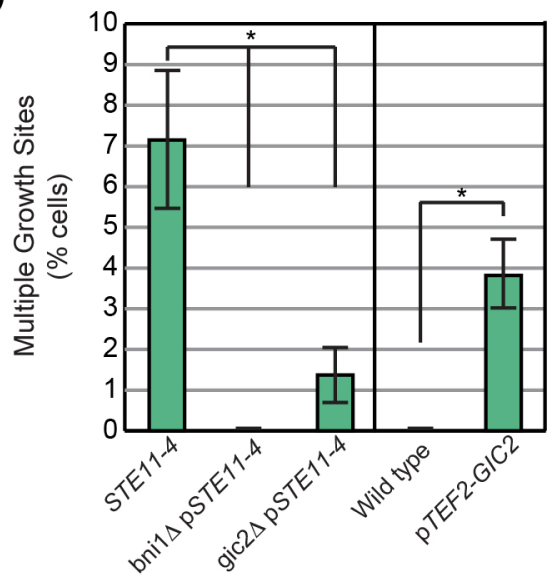

Fig._5 
Fig._6

A

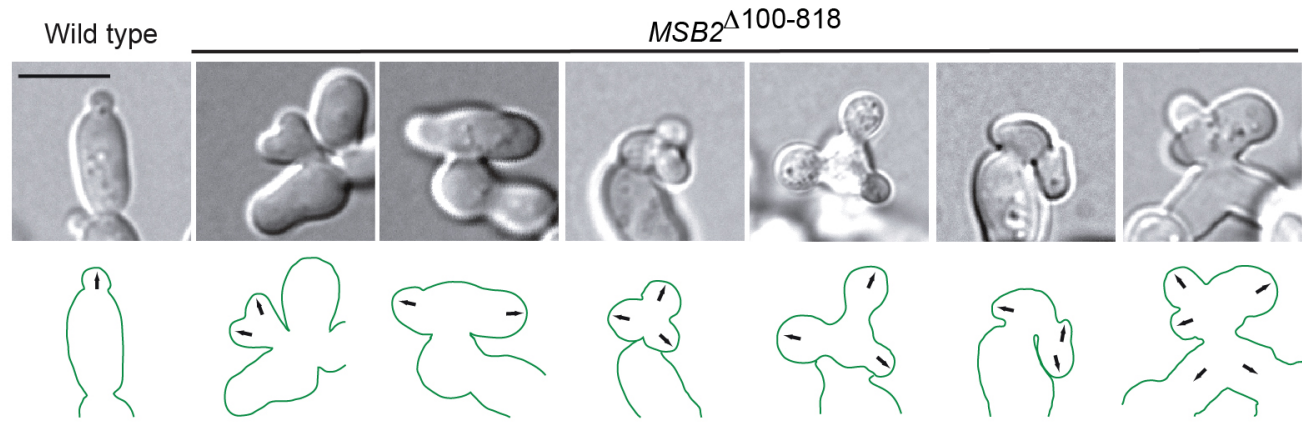

B

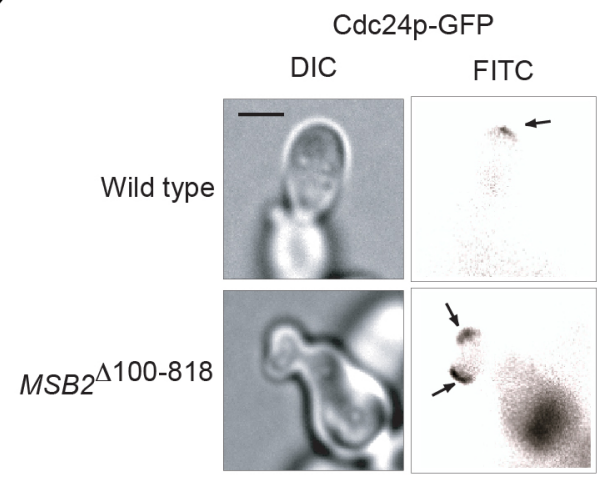

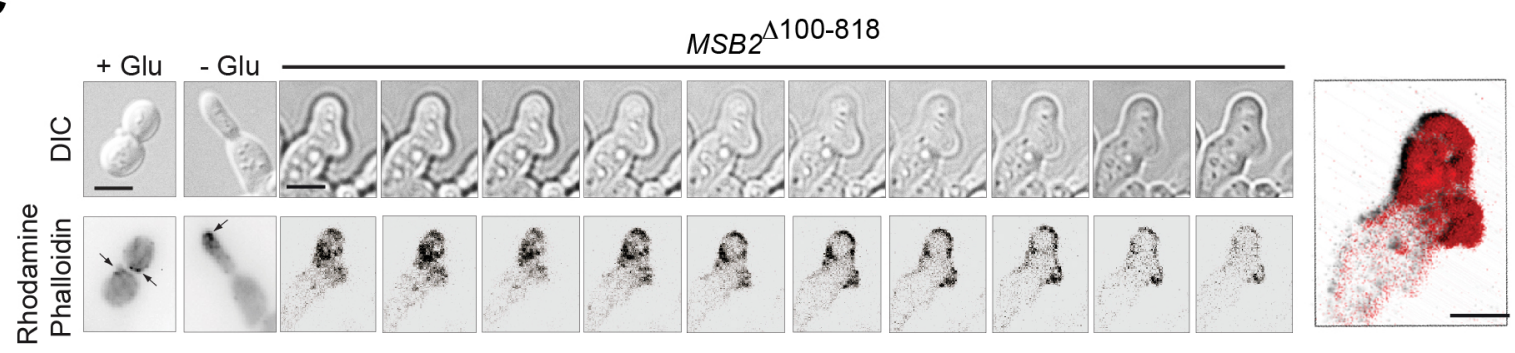

D

mist bee

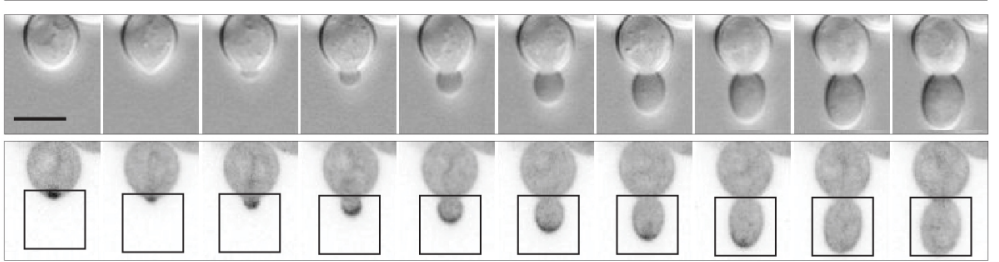

MSB2 $^{\Delta 100-818}$

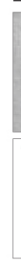

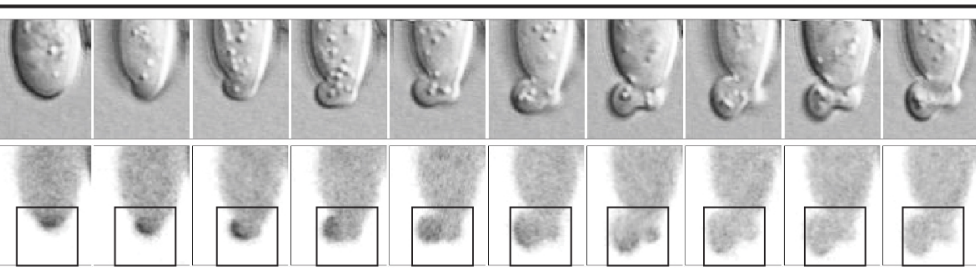

E

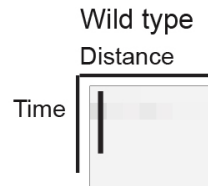

$M S B 2^{\triangle 100-818}$

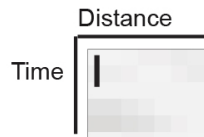

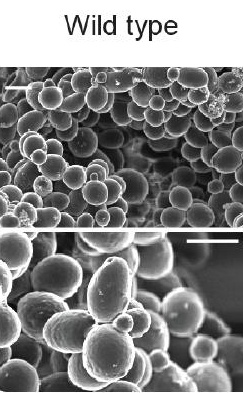
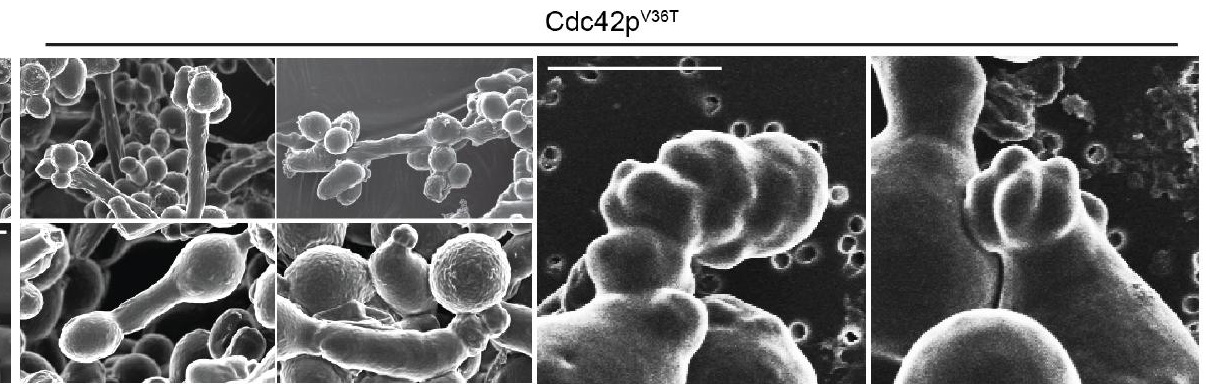


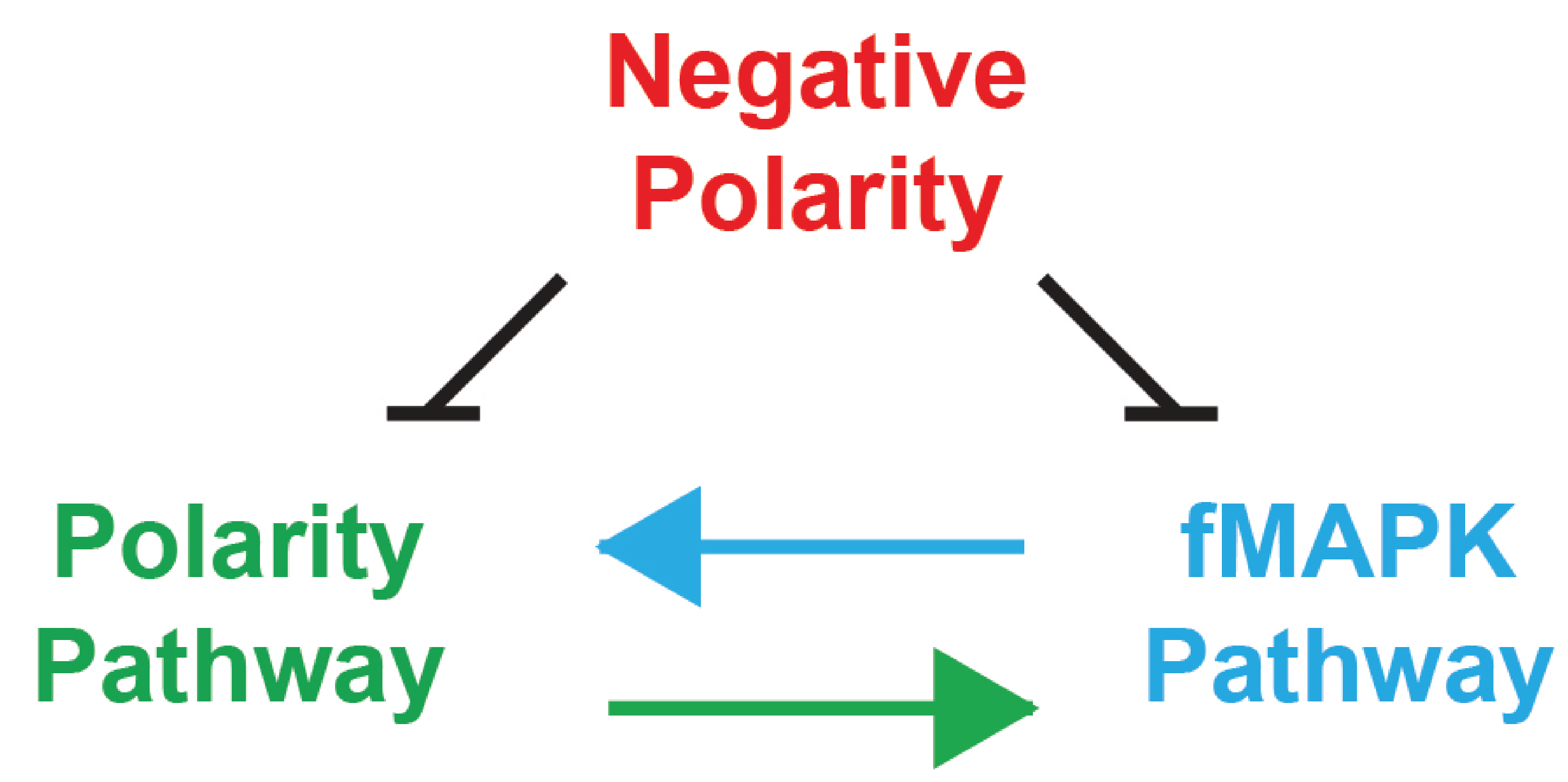

Direct Postive Feedback

Postive Feedback by Transcription 